\title{
MASTER
}

IS-T-834

\section{INDUCTIVELY COUPLED PLASMA-ATOMIC EMISSION SPECTROSCOPY: AN EVALUATION OF \\ THE USE OF NITROGEN-ARGON \\ ADMIXTURES AS PLASMA DISCHARGE ATMOSPHERES}

\author{
Joseph Christopher Zalewski
}

Based on a M. S. thesis submitted to Iowa State University

Ames Laboratory, USDOE Iowa State University

This report was prepoTICE

This report was prepared as an account of work Sponsored by the United States Govermment. Neither the Fnergy Ensol nor any of their any wark, subcontractors, or their employees, makes liability in use or responsibility for the accuracy, completeness proseses of any information, apparatus, product or process disclosed, or represents that its use would not

Ames, Iowa 50011

Date Transmitted: January 1979

PREPARED FOR THE U. S. DEPARTMENT OF ENERGY

UNDER CONTRACT NO. W-7405-eng-82 


\section{DISCLAIMER}

This report was prepared as an account of work sponsored by an agency of the United States Government. Neither the United States Government nor any agency Thereof, nor any of their employees, makes any warranty, express or implied, or assumes any legal liability or responsibility for the accuracy, completeness, or usefulness of any information, apparatus, product, or process disclosed, or represents that its use would not infringe privately owned rights. Reference herein to any specific commercial product, process, or service by trade name, trademark, manufacturer, or otherwise does not necessarily constitute or imply its endorsement, recommendation, or favoring by the United States Government or any agency thereof. The views and opinions of authors expressed herein do not necessarily state or reflect those of the United States Government or any agency thereof. 


\section{DISCLAIMER}

Portions of this document may be illegible in electronic image products. Images are produced from the best available original document. 


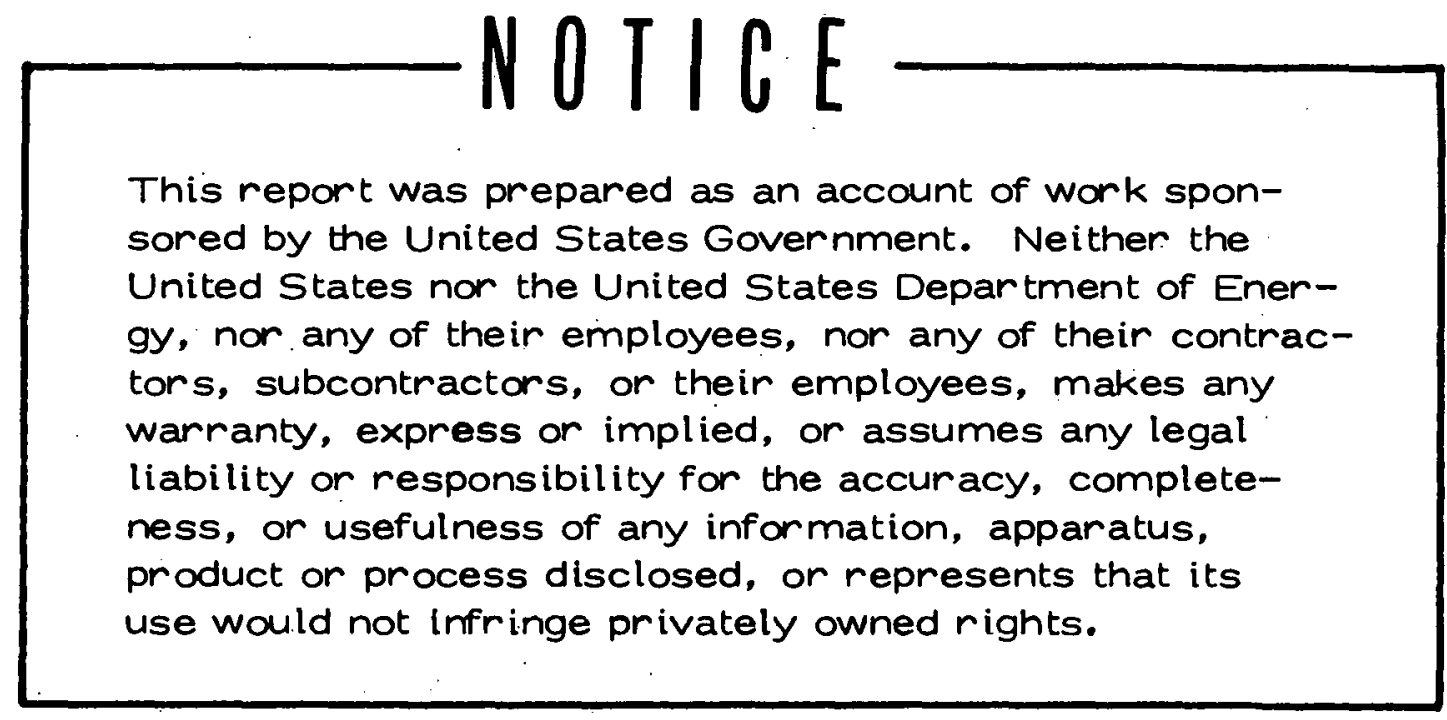

Available from: National Technical Information Service

U. S. Department of Commerce

P.O. Box 1553

Springfield, VA 22161

Price: Microfiche $\$ 3.00$ 
Inductively coupled plasma-atomic emission spectroscopy: an evaluation of the use of nitrogen-argon admixtures as plasma discharge atmospheres

by

Joseph Christopher Zalewski

A Thesis Submitted to the Graduate Faculty in Partial Fulfillment of The Requirements for the Degree of MASTER OF SCIENCE

Department: ' Chemistry

Major: Analytical Chemistry

Approved:
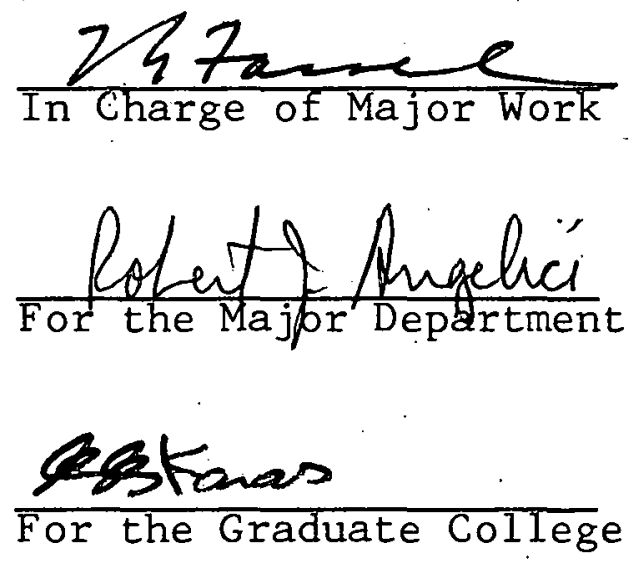

Iowa State University
Ames, Iowa 
TABLE OF CONTENTS

INTRODUCTION

Page

NOMENCLATURE

12

EXPERIMENTAL FACILITIES AND PROCEDURES

13

RESULTS AND DISCUSSION

26

SUMMARY AND CONCLUSIONS

56

SUGGESTIONS FOR FUTURE WORK

58

IITERATURE CITED

59

ACKNOWLEDGMENTS 


\section{INTRODUCTION}

Since the initial studies on the analytical applications of the inductively coupled plasma by Greenfield and associates ( 1 ) and Wendt and Fassel $(2,3)$, inductively coupled plasma-atomic emission spectroscopy (ICP-AES) has emerged as a very useful technique for the routine multielement analysis of large numbers of samples. This emergence is due primarily to the superiority of the ICP over flames as a vaporization-atomization-excitation source and the sensitivity, selectivity, and the speed of the ICP-AES technique. In order to appreciate this superiority, it is appropriate to review the operating principles and properties of these plasmas.

To understand the nature of these plasmas, it is essential to remember three simple facts: (1) plasmas are defined as gases in which a significant fraction of their atoms or molecules are ionized; (2) magnetic fields may readily react with these charged particles (electrons and ions); and (3) one of these interactions is the inductive coupling of time-varying magnetic fields with the plasma, analogous to the inductive heating of a metal cylinder. Under operating conditions currently employed in this laboratory, the plasma is formed and sustained at the open end of an assembly of quartz tubes, referred to as the plasma torch, which is surrounded by an induction coil connected 
to a high frequency current generator, as shown in Figure 1. This alternating current (I), generated by the high frequency (27.12 MHz) current generator and flowing through the induction coil, generates oscillating magnetic fields $(H)$ whose lines of force are axially oriented inside the quartz tube assembly and follow closed elliptical paths outside the coil, as can also be seen in the figure.

To initiate the plasma, the argon in the plasma support and auxiliary flows is partially ionized by a Tesla coil discharge. The resulting charged particles (electrons and ions) are induced to flow in closed circular paths due to the interaction with the magnetic field. This flow of electrons and ions, or eddy current, is analogous to a short circuited secondary of a transformer. Since both the current and the induced magnetic field are sinusoidally varying in strength with time, the electrons and ions are accelerated every half cycle. With acceleration these charged particles meet resistance to flow, which results in Joule or ohmic heating, and which, in turn, leads to additional ionization. In this way, an almost instantaneous formation of a plasma of extended dimensions occurs.

Thermal isolation if the plasma from the torch is accomplished by the vortex stabilization technique suggested by Reed $(4,5)$, which utilizes tangential introduction of the argon in the outermost quartz tube. In addition to 
F'igure 1. Schematic diagram of inductively coupled piasma. 


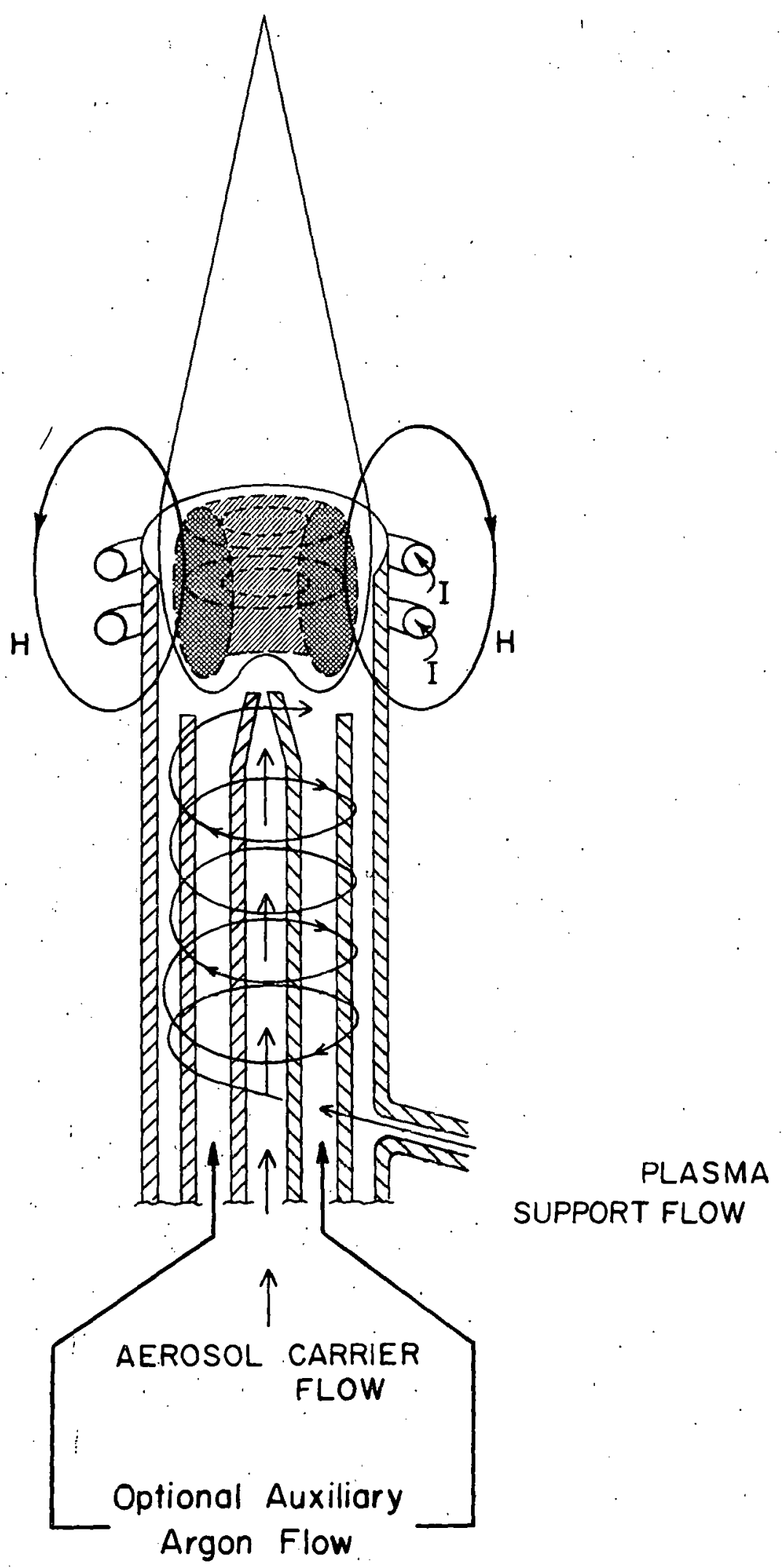


preventing the plasma torch from melting, this tangential flow also centers the plasma radially in the torch and serves as the primary sustaining flow.

\section{Fundamentals}

Sample injection into the plasma

In order for the ICP to act as an effective atomization and excitation source, the sample aerosol must be injected efficiently into the plasma and remain in the high temperature region as long as possible. However, there are forces (thermal expansion and magnetohydrodynamic thrusts, in particular) which act in opposition to sample injection into the plasma. In the ICP the gases are heated internally, causing thermal expansion in a direction perpendicular to the exterior surface of the plasma. Also, since the electric field and the induced current density are zero at the center of the plasma, and since the magnetic fields induced by both the coil and eddy currents reinforce each other at the outside of the discharge and oppose each other at the center, a magnetic compression around the sides of the plasma directed towards the center results. This compression, in turn, causes a small inward radial flow of the plasma.(6). The electrons and ions drifting toward the axis transmit their motion by momentum exchange to the neutral particles (7), which builds up kinetic pressure along the axial channel 
of the plasma. This pressure can only be converted to kinetic energy by producing an axial flow of plasma in both the upstream and downstream directions. This magnetic pumping effect, i.e., magnetohydrodynamic thrust, has been observed (8), and along with the thermal expansion thrust, opposes the entry of sample particles into the plasma.

Sample injection into the plasma has been facilitated by the utilization of (a) tangential gas introduction which provides a low pressure zone in the axial channel, thereby minimizing the magnetohydrodynamic thrust (6); and (b) the skin depth effect of induction heating, i.e., the depth at which the eddy current is reduced to $1 / e$ of its surface value, which at frequencies employed in this laboratory provides a somewhat cooler axial channel and partially overcomes the thermal expansion thrust. It should be noted that the skin depth is inversely proportional to the square root of the radiofrequency current frequency, and as the current frequency is increased, the region of maximum eddy current density moves toward the outer surface of the plasma. At frequencies in the range of 25 to $30 \mathrm{MHz}$ an incipient annular shaped plasma is formed; the degree of this annular shape can be further optimized by the carrier gas flow velocity and proper injection orifices (9-11).

Properties of the ICP

According to measurements in this laboratory (12), by 
the time sample particles reach the observation height of 15 to $20 \mathrm{~mm}$ above the load coil, they have had a residence time of approximately $2 \mathrm{msec}$ at temperatures ranging downward from $7000^{\circ}$ to $5500^{\circ} \mathrm{K}$. Both the residence times and the temperatures are approximately twice as great as those found in nitrous oxide-acetylene flames, the hottest flame commonly used in analytical spectroscopy. This combination of high temperature and relatively long sample-plasma interaction times should lead to complete sample vaporization and a high degree of atomization. Also, because the atoms are released in a noble gas environment, free atom depopulation processes, such as monoxide formation, should be minimized, and consequently, the atom lifetime should be longer than in flames.

The plasma possesses other unique advantages. For example, after the free atoms are formed, they flow downstream in a narrow cylindrical radiating channel. The optical aperture of conventional spectrometers can be readily filled by this channel resulting in a more effective utilization of the emitted radiations. In addition, since the temperature across the central radiating channel is relatively uniform at normal observation heights (12), and the number density of analyte free atoms in the argon surrounding this channel is far lower, analytical calibration curves over several orders of magnitude change in concentration may be obtained when proper detection and measurement systems are used. 
With respect to non-spectral interelement interferences, the combination of the relatively high temperature and analyte residence time, along with the free-atom formation in a noble gas environment, should overcome many of these effects found in flames. These expectations have been confirmed in the observation of several classical interelement interference effects (13) and in the application of ICP-AES for the determination of several metals in low and high alloy steels (14).

The above listed properties support the use of an ICP as a vaporization-atomization-excitation source for atomic emission spectroscopy, and the analytical utility of ICP-AES. has been documented in several recent reviews (15-19).

However, due to the increasing acceptance of the inductively coupled plasma in argon for spectrochemical analysis, plasma discharges operated under mixed gas conditions have been examined to a rather limited extent. For example, the use of economical diatomic gases, especially nitrogen, mixed with argon as ICP discharge atmospheres for spectrochemical. purposes has been restricted to the reports of Greenfield (20-22), Greenfield and Smith (23), Capitelli. et al. (24), and 'Iruitt and Rubinson $(25,26)$.'

Although Reed $(4,5)$ first generated a stable argon ICP at atmospheric pressure and applied mixtures of argon and diatomic gases to the melting and growing of refractory 
crystals, the spectrochemical utility of the mixed gas ICP was not investigated. The use of nitrogen, oxygen, helium, and air in either the plasma coolant or carrier gas flow was examined by Greenfield $(20,21)$, and observations of the effects of these gases on the emission intensity of selected spectral lines and the background were summarized.

As a result of these studies, Greenfield's laboratory has become the major proponent for spectrochemical analysis in nitrogen-argon plasmas as opposed to those operated in argon atmospheres. This preference was based on the observation of an improvement in the signal to noise ratio $(S / N)$ when nitrogen replaced argon as the coolant gas in the concentric, three-gas flow pattern employed in the plasma torch. Greenfield also stated that "the net signal and hence the sensitivity of all the lines studied is greater for nitrogen, implying that the tail-flame is hotter (22)."

Capitelli et al. (24) examined the extent of decomposition of aluminum oxide particles injected into an ICP supported either with argon or argon containing 4 or $8 \%(\mathrm{v} / \mathrm{v})$ nitrogen. The authors observed that while the extent of decomposition was higher in the argon-nitrogen plasmas at short distances, the maximum extent of decomposition of the particles was lower than in the argon plasma due to the effect of the nitrogen on the shape of the resulting discharge. In addition, the experimentally determined extent 
of decomposition in the $\mathrm{Ar}-\mathrm{N}_{2}$ induction coupled plasmas was lower than theoretically predicted.

Truitt and Robinson $(25,26)$ examined the effects of nitrogen and other gases mixed with argon on the emission intensities of molecular fragments, i.e., $\mathrm{C}, \mathrm{H}, \mathrm{CN}$, and $\mathrm{C}_{2}$, when organic compounds were introduced into an ICP. These authors observed that nitrogen could be introduced into the plasma coolant and carrier gas flows and that the introduction of the sample into either of these flows had little effect on the intensity of the emission observed. Also, the addition of nitrogen to the torch gas flow increased the $\mathrm{CN}$ and decreased the $\mathrm{C}$ line intensities.

In their earlier.paper (25), Truitt and Robinson examined the effects of different operating conditions on the emission intensity of the background and claimed that their torch gave a lower background and exhibited greater freedom from band structure than the torch employed by Greenfield et a1. (1). This was disputed by Greenfield and Smith (27), who suggested that the plasma characteristics observed by the former were probably peculiar to the equipment used.

In fact, it should be realized that there does not exist a unique configuration for the ICP, but that various versions exist, e.g., either teardrop or annular shaped. Furthermore, the degree to which an annular shaped plasma is formed is dependent upon the configuration of the plasma torch tubes, 
the tangential velocity component of the plasma coolant gas, the frequency of the current generator, and the flow velocity of the aerosol carrier gas. Investigators have employed different sets of the above mentioned parameters to achieve varying degrees of annularity and sample residence times. In fact, Greenfield et al. (28) found that an annular shaped plasma may be formed with laminar or tangential introduction of the plasma coolant gas when the base of the discharge is flattened with an auxiliary argon flow.

Another distinguishing factor between various ICP's is the mode in which they are generated. For example, the plasma generator may be a self-excited (free-running) oscillator, with the plasma acting as part of the resonant circuit. Alternately, the same type of generator may be used and coupled to the plasma via an impedance matching network. A third alternative is based on the crystal control of the operating frequency and the use of a tuning-coupling circuit for impedance matching purposes. In this case, the plasma is a less active circuit element.

Inherent in the operation of the plasma under various conditions is a variation in the properties of the plasma source itself, as the above mentioned dispute indicates. Another example can be found in the relatively poor sample introduction efficiency and the difference in interelement interferences observed in teardrop shaped plasmas as compared 
to annular ones $(3,13,29,30)$. Further evidence that the operating conditions influence the properties of the plasma may be found in the somewhat different interference effects due to easily ionizable elements observed with the freerunning $(31,32)$ and crystal-controlled $(13,30)$ plasma generators, as well as the greater tolerance for large amounts of water of the former (18) over the latter $(18,33)$. While the extent of these differences may indeed be dependent on the plasma configuration and on the method of plasma generation, other factors may play a role as well. Thus, the power dissipated in the plasma, the torch design, the method of sample introduction, and the height of observation may all have an effect.

None of the previous spectrochemical applications of nitrogen-argon plasmas were performed under conditions currently employed in this laboratory. The purpose of this investigation was, therefore, to examine the analytical utility of the ICP-AES technique when a crystal-controlled, nitrogen-argon, annular shaped ICP is employed. By necessity, this evaluation is based on a comparison of the properties of the ICP operated in argon and mixed nitrogenargon atmospheres. 


\section{NOMENCLATURE}

The accepted nomenclature in this laboratory (34) for the three gas flows of the plasma torch is also shown in Figure 1. However, an inconsistency arises when nitrogenargon plasmas are employed. This is due to the experimentally observed fact that the plasma can be operated with only nitrogen in the outermost (plasma support) gas flow provided that an auxiliary argon gas flow is supplied. The auxiliary argon gas flow, in this case, is responsible for sustaining the ICP. Therefore, the plasma support gas flow and the auxiliary argon flow are referred to as the (plasma) coolant and auxiliary plasma gas flows, respectively, in all subsequent discussions. 
EXPERTMENTAL FACILITIES AND PROCEDURES

\section{Apparatus}

\section{ICP-AES system}

In order that both wavelength scans and direct digital signal measurement could be performed, two ICP-AES systems differing only in the modes of spectral isolation and data acquisition were employed. The major components of the two systems are described in Table 1.

For the ARL QVAC 127 direct reading spectrometer (System 1) the exit slits that isolated the spectral lines along the focal curve were fixed in position and thus measurements were restricted to those lines programmed on the instrument. Small changes in the wavelength region sampled by each of the exit slits, analogous to scanning over the spectral line, are produced by small, computer-controlled changes in the angle of incidence of the source radiation upon the grating.

The Jarrell-Ash spectrometer (System 2) was employed for wavelength scans over the spectral range of interest. In the case where the two systems were used to support the results of each other, identical operating conditions, i.e., observation height, slit widths, forward power, sample uptake rate, ctc., were employed.

The operating conditions employed throughout this study are listed in Table 2. 
Table 1. Experimental facilities

Component Description

Plasma power supply

Sample introduction systems

Pneumatic nebulization

Ultrasonic nebulization

Transducer

Nebulization chamber

Gas handling system
Plasma Therm, Inc. (Kressen, NJ) Model HFS 3000 D $\mathrm{RF}$ generator with a crystal-controlled frequency of $27.12 \mathrm{MHz}$ and a $3000 \mathrm{~W}$ maximum forward power rating. The water cooled load coil, made from 3 turns of $1 / 8$. inch $0 . d$. copper tubing, was $7 / 8$ inch $0 . d$.

Right-angle pneumatic nebulizer as described by Kniseley et al. (35) with the Teflon and borosilicate glass nebulization chamber as described by Larson et al. (13). The aerosol was fed directly to the plasma without desolvation.

Channel Products, Inc. (Chagrin Falls, $\mathrm{OH}$ ) Model CPMT, Channel 非8000 lead zirconate titanate transducer with protection/acoustic coupling as described by 0lson et al. (33).

The nebulization chamber employed was modified by incorporating a Teflon baffle to prohibit transport of larger droplets. The sample transport system and desolvation system were those described by Olson et al. (33).

Shown schematically in Figure 2 and described in the text. 
Plasma torches

Fused quartz

Demountable

Spectrometers
Ames Laboratory designed concentric quartz tube configuration as described by Fassel and Kniseley (15).

Shown in Figure 3 and described in text.

System 1

Applied Research Laboratories (Sunland, CA)

Model QVAC-127 direct

reading polychrometer.

The grating, with 2160

grooves $/ \mathrm{mm}$, is blazed for

the $170-215 \mathrm{~nm}$ region.

The spectrometer is evac-

uated and covers the

wavelength range from 170

to $407 \mathrm{~nm}$.

Data acquisition system (in utilization sequence)

Photomultipliers

Signal amplifiers

RCA 1P21, 1P28, or their equivalents.

Keithley Instruments

(Cleveland $\mathrm{OH}$ ) Model

1800 remotely program-

mable $\mathrm{i} / \mathrm{v}$ converters (one' per channel).

Analog/digital converter
Ames Laboratory constructed log amplifier.
Zeltex (Concord, CA) Model 72112 bit A/D converter/ multiplexer.
System 2

Jarre11-Ash (Waltham, MA) Model 78-466 1.0meter Czerny-Turner mount scanning spectrometer. The grating, with 1180 grooves $/ \mathrm{mm}$, is blazed for $250 \mathrm{~nm}$. 
Table 1. (continued)

Minicomputer

Computer interface: system

Data output
Digital Equipment Corporation (Maynard, MA) Model PDP $8 /$ e.

Heath-Schlumberger (Benton Harbor, MI) Model EU-801E.

Decwriter II (Digital

Equipment Corporation)

sends and receives 30

characterst second or Remex er
Model RAF-6375 high speed

paper tape punch, reads

300 and punches 75

characters/second.
Soltec Corporation

(North Hollywood, CA)

Model BW-210 X-Y record- 
Table 2. Experimental conditions employed in this study

Component.

Operating conditions

Generator

Forward power

Reflected power

$1100 \mathrm{~W}$

$5 \mathrm{~W}$

Gas flow rates

(P lasma) coolant Auxiliary plasma Aerosol carrier

16 to 0 l/min Ar, 0 to $16 \ell / \mathrm{min}_{2}$ $1.5 \mathrm{l} / \mathrm{min} \mathrm{Ar}$ $1.0 \mathrm{l} / \mathrm{min}$ Ar

Sample uptake rate

Pneumatic

nebulization

Ultrasonic

nebulization

$2.2 \mathrm{~m} . l / \mathrm{min}$

$2.5 \mathrm{~m} / / \mathrm{min}$

Transducer frequency $1.45 \mathrm{MHz}$

Spectrometer slit widths

Entrance

Exit

Analytical wavelengths
$20 \mu \mathrm{m}$

$50 \mu \mathrm{m}$

a I ine originates from neutral atom state.

bII line originates from singly ionized state. 
Gas handling system

The major components of the gas handling system employed in the present study, which enabled the coolant flow to be varied continuously from $100 \%$ argon to $100 \%$ nitrogen, are shown schematically in Figure 2. The apparatus utilized for the flow control of the argon gas has been previously described (35). The only modification to the argon gas flow control system involved the rerouting of the plasma coolant gas flow through a MECO inert gas mixer as the major component flow prior to introduction into the plasma torch assembly. The nitrogen gas flow, which was introduced as the minor component, was controlled by means of needle valves and flow meters. Two flow meters were employed in order to improve the reproducibility of the nitrogen gas flow rate over the range of flows ( 0 to $16 \mathrm{l} / \mathrm{min}$ ) utilized. The Brooks flow meter (tube $\mathrm{R}-2-15-\mathrm{B}$, Brooks Instrument Division, Hatfield, PA) was used for the lower ( $\leqq 2 / \mathrm{min}$ ) nitrogen flow rates, whilc the Mathesnn flow meter (tube 605, Matheson Gas Products, Joliet, IL) was used for the higher flow rates. The aerosol carrier gas flow could also be varied from $100 \%$ argon to $100 \%$ nitrogen using the same apparatus. In this case, however, the argon carrier gas flow was rerouted through the gas mixer. 


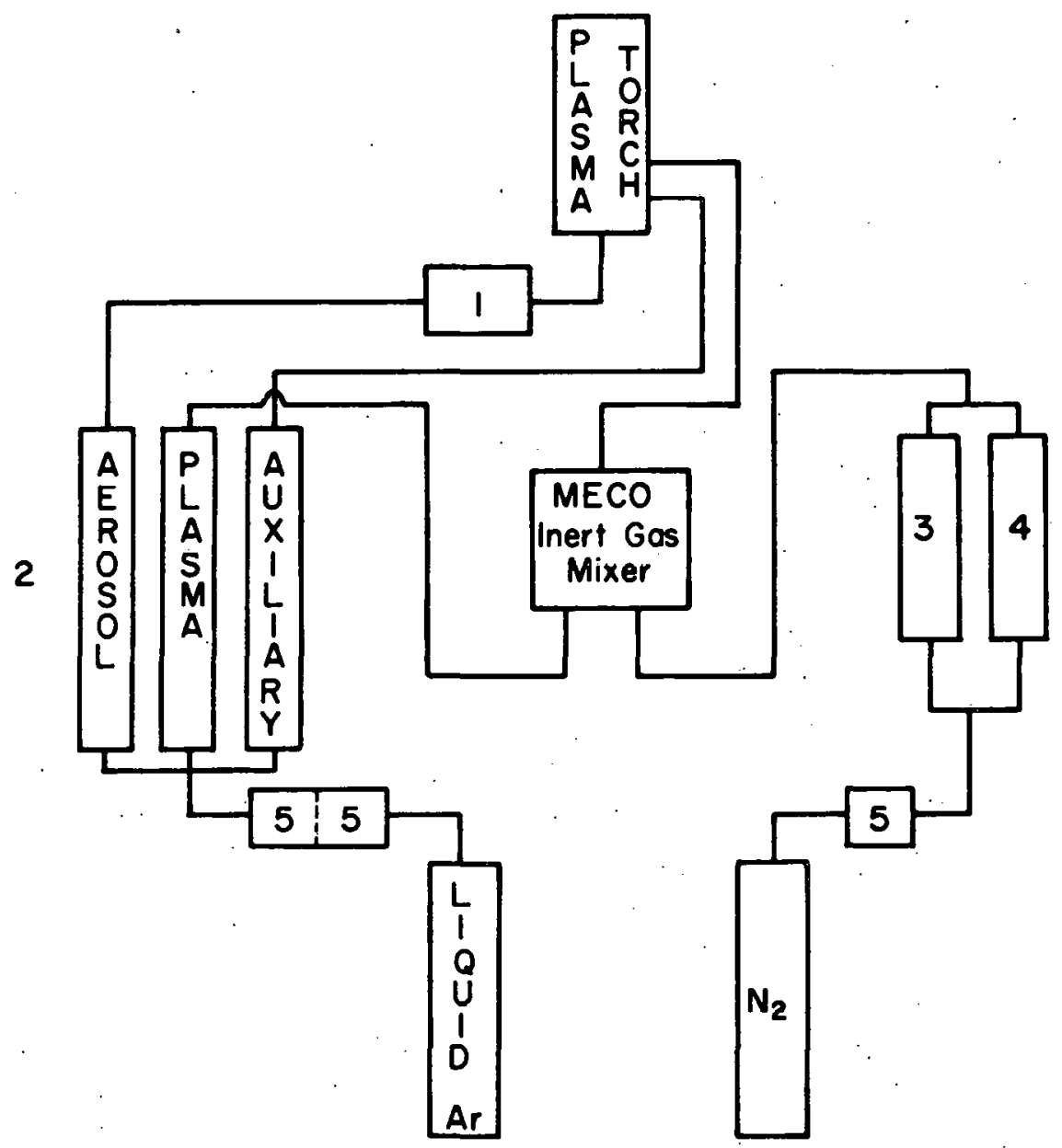

1) Sample Nebulization System (Ultrasonic w/ Desolvation or Pneumatic)

2) Matheson Rotometers

3) Brooks R-2-15-B Rotometer (for $\mathrm{N}_{2}$ flow rates $\leq 2 \mathrm{I} / \mathrm{min}$ )

4) Motheson 605 Rotometer (for $\mathrm{N}_{2}$ flow rates $>2 \mathrm{l} / \mathrm{min}$ )

5) Two-Stage Regulators

Figure 2. Schematic diagram of gas handling system. 
Demountable plasma torch

The standard plasma torch (15) utilizes a fused quartz design with tangential gas flow, hence repair is difficult if wall damage occurs. The demountable torch, a modification of previous designs (36-39), was constructed to obviate this. The torch assembly, shown in Figure 3, incorporated the following important design features:

1) The 'O'-ring seals facilitated the interchange of the precision quartz tubes (Wilmot Glass Company, Buena, $\mathrm{NJ}$ ) and ensured the concentricity of the torch tubes.

2) The Lexan (Rohm and Haas, Philadelphia, PA) base was constructed in two sections and assembles via a screw thread. This feature permitted independent vertical adjustment of the auxiliary and aerosol tubes of the torch with respect to the coolant tube.

3) A micrometer adjust (DAEDAL, Inc., Pittsburgh, PA), to which the torch base was mounted, allowed the precise vertical placement of the torch within the load coil, and a positioning bracket mounted to the plasma shielding box provided a means of centering the torch within the coil.

4) The Teflon directional flow controller provided additional benefits by eliminating some glass shop work and by facilitating plasma initiation. The flow controller used in the present study had a groove depth of $1 \mathrm{~mm}$, a dimension considered critical to provide sufficient cooling for the 


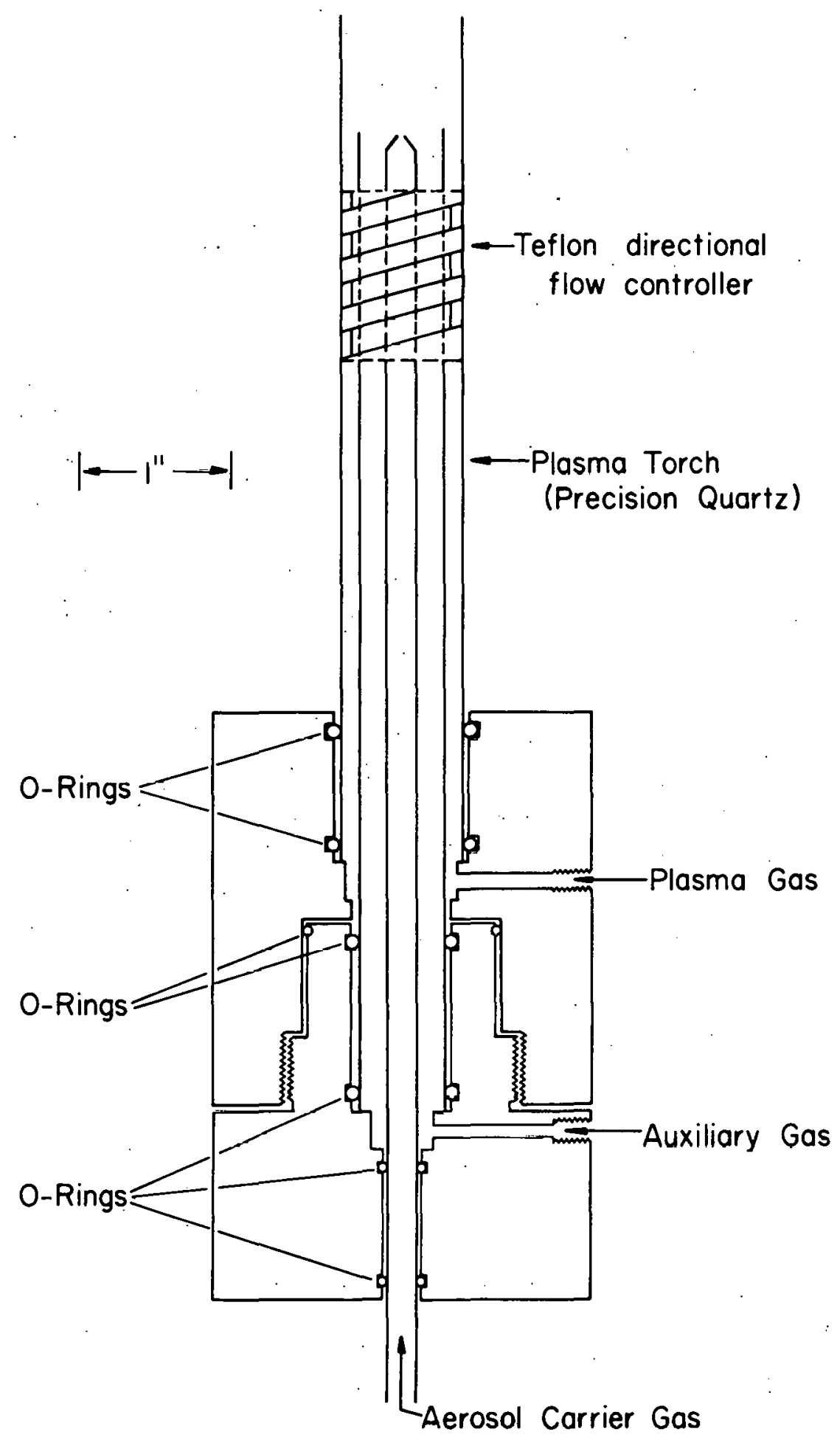

Figure 3. Demountable plasma torch. 
inner wall of the outermost quartz tube, a groove width of approximately $4 \mathrm{~mm}$ and a pitch of $1 / 2$ revolution/inch. With the exception of some discoloration, the Teflon exhibited no deterioration after several hours of use.

\section{Procedures}

Plasma initiation

Because the ICP was operated under three different gas flow patterns, i.e., argon, argon with nitrogen coolant gas, and argon with nitrogen aerosol carrier gas, subtle differences in the operating conditions and techniques for obtaining a stable plasma discharge existed. These differences are presented for each of the gas flow patterns employed. The procedure for argon ICP initiation is referred to as the normal procedure.

Argon ICP (normal) To start the plasma it is necessary to purge air from the nebulization chamber and the torch assembly. After about a one minute purge at normal gas flow rates, the aerosol carrier gas is turned off. The RF power is then slowly increased and at approximately $500 \mathrm{~W}$ forward power the Tesla coil discharge is initiated. The plasma starts quickly when sufficient power $(\sim 700 \mathrm{~W})$ is available to sustain the plasma. After the power is raised to its maximum set point the aerosol carrier flow valve is opened and the auxiliary plasma argon valve is closed. 
Argon ICP with nitrogen coolant gas The plasma is initiated following the normal procedures given above. Nitrogen gas is then slowly introduced into the plasma coolant gas stream, and the auxiliary plasma gas flow is increased to approximately $1.5 \mathrm{l} / \mathrm{min}$. The rate of introduction of nitrogen must be slow enough to allow the automatic servo-driven tuning and loading capacitors to adjust to the changing impedance characteristics of the load. The nitrogen gas flow was then increased to approximately $16 \mathrm{l} / \mathrm{min}$ while the argon coolant gas flow was simultaneously decreased to zero. The changeover from $100 \%$ argon to $100 \%$ nitrogen in the coolant gas flow required less than one minute.

Argon ICP with nitrogen aerosol carrier gas The introduction of nitrogen into the carrier gas flow required operating conditions not normally employed. For example, the plasma torch had to be raised so that the top of the intermediate tube was positioned approximately even with the base of the induction coil. In addiliun, d $1.5 \mathrm{~mm}$ capillary-tipped aerosol tube had to be employed.

With these conditions met, the plasma was then initiated employing the normal procedures, except that the auxiliary plasma argon flow was increased to approximately $1.5 \mathrm{l} / \mathrm{min}$. prior to introducing the carrier gas. The nitrogen was then abruptly introduced as the carrier gas with a $1.0 \mathrm{l} / \mathrm{min}$. flow rate. Alternately, argon was introduced as the carrier gas, 
and nitrogen was subsequently added while decreasing the argon gas flow rate.

\section{Sample preparation}

Stock solutions were prepared by dissolving pure metals or reagent grade salts in dilute acid or deionized distilled water (DDW) (Barnstead PCS system, Boston, MA). With the exception of the study on the effect of the matrix on the net analyte emission intensity, the reference blank solution employed was $1 \%$ (vol) concentrated, redistilled, AR grade nitric acid. Analyte solutions were prepared by appropriate addition of the stock solution to aliquots of the fresh reference blank solution. The multielement stock solution, used for the detection limit study, and all working solutions were prepared in a Class 100 horizontal laminar flow work station (Agnew-Higgins, Inc., Garden Grove, CA), using Class A volumetric glassware. The glassware was leached for at least 24 hours with $1 / 10(\mathrm{v} / \mathrm{v}) \mathrm{HCl} / \mathrm{DDW}$ and rinsed four times with DDW immediately before use. Freshly made solulions were immediately transferred to polyethylene sample bottles which had been leached for at least 72 hours with $1 / 1(\mathrm{v} / \mathrm{v})$ $\mathrm{HNO}_{3} / \mathrm{DDW}$, rinsed four times with $\mathrm{DDW}$, and air dried in the laminar flow work station. Reference solutions with elemental concentrations less than $1 \mu g / m l$ were prepared no more than a few days before they were to be used to avoid adsorption and contamination problems normally associated with the 
storage of low concentration solutions.

Detection limits

The detection limits reported correspond to the concentration of analyte required to give an average net emission intensity equal to three times the standard deviation of the background emission. This definition is in accordance with IUPAC recommendations (41). The average value and the standard deviation of the background emission were determined first, from ten consecutive 20-second measurements of the average photocurrents produced when the blank was nebulized. The average value of the background plus analyte emission was determined next, in the same way, but while nebulizing the multielement reference sample. 


\section{RESULTS AND DISCUSSION}

\section{Physical Characteristies}

\section{Appearance}

The volume of a nitrogen gas added to the plasma coolant gas flow had a pronounced effect on the size and shape of the plasma discharge as can be seen in Figure $4(a-i)$. Several reasons for this physical size reduction of the ICP have been postulated. For example, Dickinson (42) stated that when argon is diluted with a substance of lower electrical conductivity, such as nitrogen $\left(\sigma_{\mathrm{Ar}}=20-100 \mathrm{ohm}^{-1} \mathrm{~cm}^{-1}, \sigma_{\mathrm{N}_{2}}=4-20\right.$ $\mathrm{ohm}^{-1} \mathrm{~cm}^{-1}$ ), the lower conductivity of the diluent causes the decrease in the plasma radius and the increase in the skin depth. Greenfield and Smith (27) have attributed the above phenomena to a thermal pinch applied to the plasma, i.e., the dissociation of a polyatomic gas absorbs energy; therefore, the outside of the plasma becomes cooler and less conducting, and a smaller more intcnse plasma results. The effect of the thermal pinch on the plasma was also noted by Thorpe (43), who attributed this pinch to the increased thermal conductivity of nitrogen over argon.

A thermal pinch can also be observed when nitrogen is introduced as the aerosol carrier gas, as can be seen in Figure $4(j)$. However, in this case the axial channel in the plasma becomes clearly visible. In fact, the appearance of 


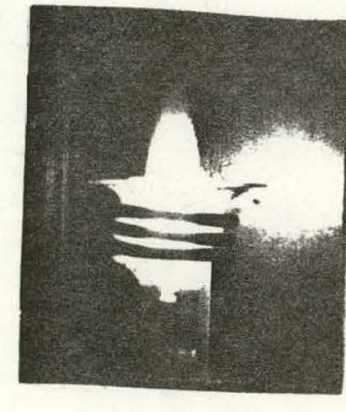

a. $\quad 0_{2}^{\circ} \mathrm{N}_{2}$

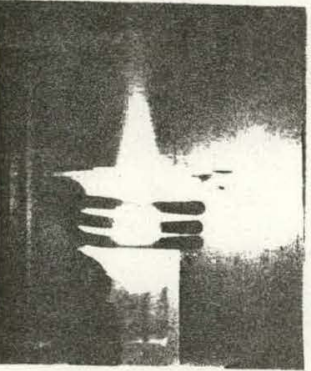

f. $9 \% \mathrm{~N}_{2}$

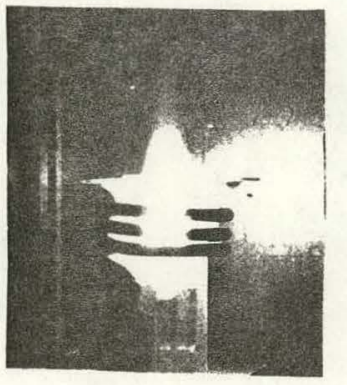

b. $3 \% \mathrm{~N}_{2}$

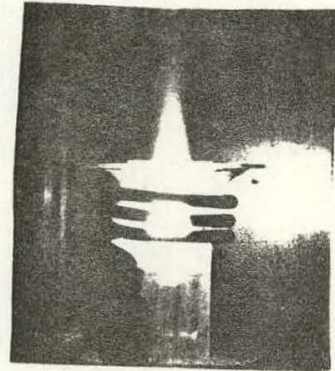

g. $25 \% \mathrm{~N}_{2}$

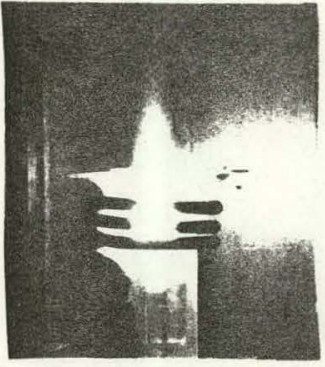

c. $\quad 4.5 \% \mathrm{~N}_{2}$

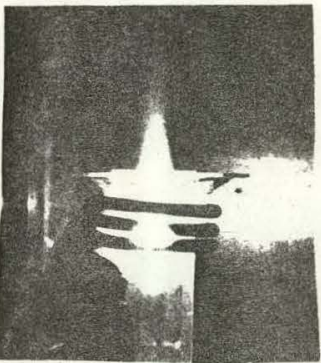

h. $50 \% \mathrm{~N}_{2}$
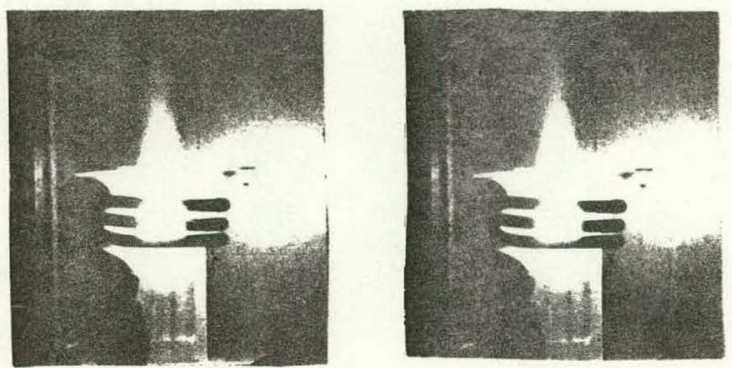

d. $6 \% \mathrm{~N}_{2}$

e. $7.5 \% \mathrm{~N}_{2}$
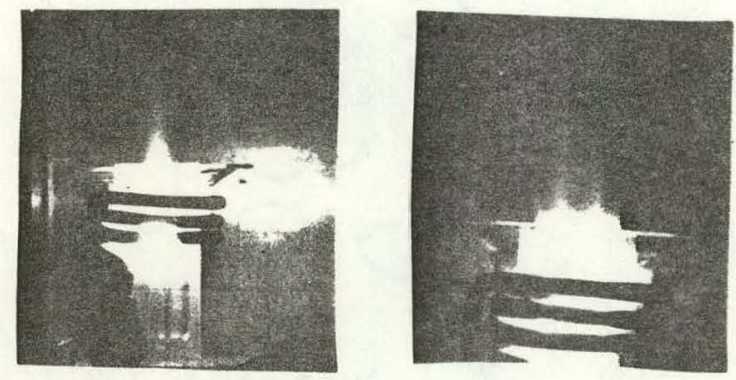

Figure 4. Effect of per cent nitrogen in the plasma coolant gas flow (a-i) and ritrogen in the aerosol carrier gas flow $(j)$ on the appearance of the ICP. 
the plasma with nitrogen aerosol gas is similar to that of the plasma when typical color-emitting analytes, e.g., sodium, are introduced. This, in turn suggests that the shape of the plasma is partially due to the increasing diffusion of the nitrogen gas into the argon sheath with distance. Stability In evaluating the relative merits of the ICP operated with nitrogen gas in one of the torch flows, the stability of the plasma discharge, defined in terms of incident power requirements for dry and wet aerosol, is an important consideration. The cost of the generator is directly related to the power requirements of the plasma, and the tolerance for nebulized water allows the use of simple pneumatic nebulizers.

The plasma was evaluated under the three gas flow patterns and two torch positions, i.e., the torch positioned so that the top of the intermediate tube lay either approximately $2 \mathrm{~mm}$ below the load coil (Normal Torch) or even with the base of the load coil (Raised Torch). The minimum power at which these experiments were performed was $800 \mathrm{~W}$, generally lower than the minimum forward power at which spectrochemical analyses are performed. The results of this study are listed in Table 3 . 
Table 3. Incident $\mathrm{RF}$ power, requirements

Gas flow pattern Dry aerosol Wet aerosola

Normal Torch

$\begin{array}{lcc}\text { Argon } & 800 \mathrm{~W} & 800 \mathrm{~W} \\ \text { Nitrogen coolant } & 800 \mathrm{~b} & 950 \mathrm{~W} \\ \text { Nitrogen carrier } & - & -\end{array}$

Raised Torch

Argon

Nitrogen coolant

Nitrogen carrier

$800 \mathrm{~W}$
$800 \mathrm{~W}$
$1250 \mathrm{~W}$

$800 \mathrm{~W}$

$800 \mathrm{~W}$

$1450 \mathrm{~W}$

\footnotetext{
apneumatic nebulization of water.

$\mathrm{b}_{\text {ICP }}$ was not maintained.
}

The results of this study indicated that although there is a slight superiority for the plasma operated in argon at either torch position over the plasma with nitrogen coolant gas at the Normal Torch position, this superiority vanishes when the latter plasma is operated with the torch raised. However, when nilrogen was introduced as the aerosol carrier gas, the plasma was extinguished at the Normal Torch position, and even when the torch was raised, approximately twice as much power was required to maintain the plasma with pneumatically nebulized water. The author believes that the extinguishing of the plasma was due primarily to the expansion of the nitrogen carrier gas stream prior to reaching the discharge; hence, the utilization of the raised 
torch, the capillary-tipped aerosol tube, and the auxiliary plasma gas flow contributed in minimizing this expansion. It should also be noted that the results obtained for the ICP operated with nitrogen coolant gas contradict the observations of previous workers. For example, Greenfield (20) observed that the plasma could not be operated with more than $20 \%$ nitrogen in the coolant gas flow when a $2.5 \mathrm{KW}$ generator was employed. Greenfield stated that the use of $100 \%$ nitrogen in the coolant flow probably required the use of a larger generator, and therefore, his laboratory used a 15 $\mathrm{KW}$ generator (28). Boumans (44) also states that the operation of the plasma in the 0.5 to $1.5 \mathrm{KW}$ range precludes the use of anything but argon in the gas flows. Although these contradictory results may be due to the peculiarities of the various ICP. sources employed, i.e., different modes of operation were used, it is noteworthy that the plasma could be maintained when a generator which was a self-excited oscillator and coupled to the plasma via an impedance matching network (described previously $(10,42)$ ) was utilized. 
Spectrochemical Properties

Effect of $\% \mathrm{~N}_{2}$ in plasma coolant gas fl low on analyte emission intensity

The net analyte emission intensity, i.e., the intensity of the analyte plus the background emission minus the intensity of the background emission, was measured for several spectral lines with increasing nitrogen in the plasma coolant gas flow and with increasing observation height under the operating conditions given in Table 2 and with the plasma torch in the raised position. The net analyte emission intensity obtained at an observation height of $10 \mathrm{~mm}$ in the argon plasma was arbitrarily set to 1.0 relative intensity units. The remaining net emission intensity data were then normalized to this value.

In order to better appreciate the combined effects of the $\% \mathrm{~N}_{2}$, i.e., the flow rate of nitrogen gas divided by the flow rate of nitrogen plus argon in the plasma coolant gas flow, and the observation height on.the net analyte emission intensity, the relative intensity data for several speetral lines were plotted versus both $\% \mathrm{~N}_{2}$ and observation height. The response surfaces obtained for $\mathrm{Cd} I(228.80 \mathrm{~nm})$ and $\mathrm{Cd}$ II $(226.50 \mathrm{~nm}), \mathrm{Ni} I(351.51 \mathrm{~nm})$ and $\mathrm{Ni}$ II $(231.60 \mathrm{~nm}), \mathrm{Pb} \mathrm{I}$ $(405.78 \mathrm{~nm})$ and $\mathrm{Pb}$ II $(220.35 \mathrm{~nm})$, and $\mathrm{Zn} \mathrm{I}(213.86 \mathrm{~nm})$ and Zn II (202.55 nm) are shown in Figures 5, 6, 7, and 8, respectively. 

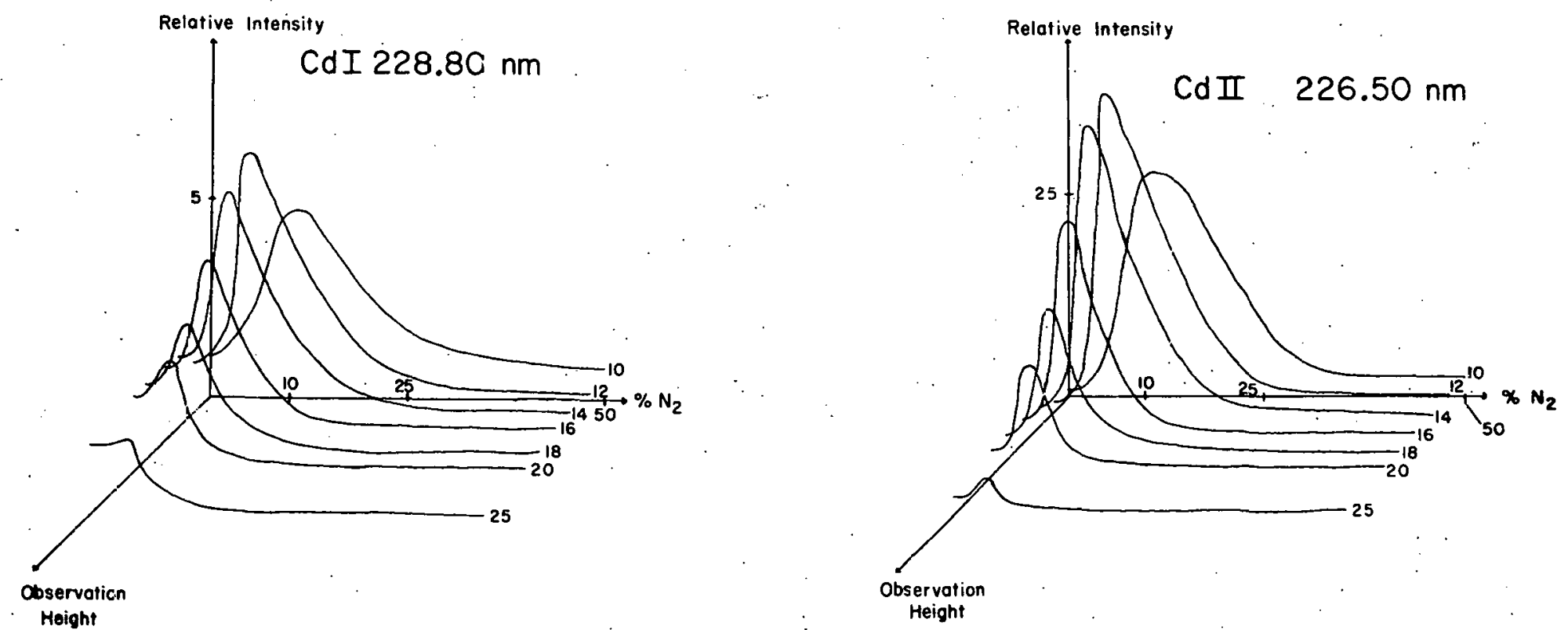

Figure 5. Effect of $\% \mathrm{~N}_{2}$ and observation height $(\mathrm{mm})$ on the relative intensities of the cadmium atom and ion spectral lines at $228.80 \mathrm{~nm}$ and $226.50 \mathrm{~nm}$, respectively. 

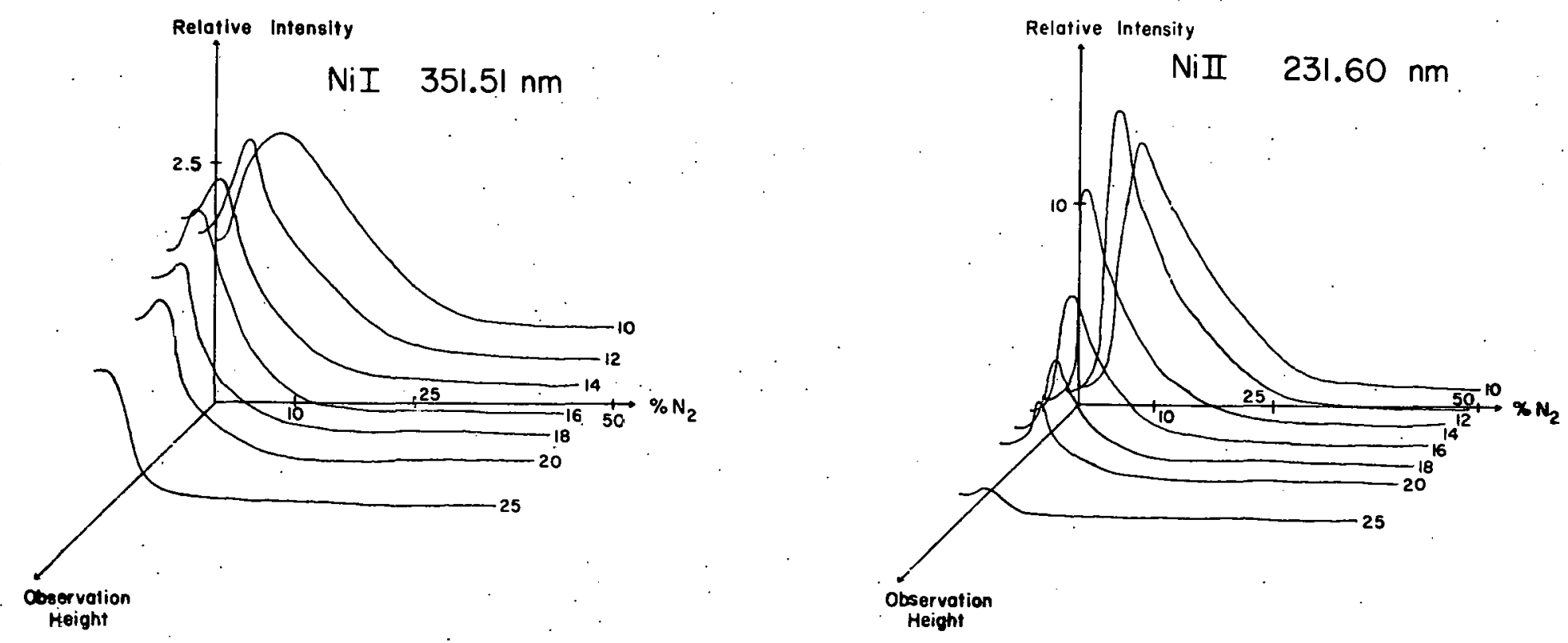

Figure 6. Effect of $\% \mathrm{~N}_{2}$ and observation height $(\mathrm{mm})$ on the relative intensities of the nickel atom and ion spectral lines at $351.51 \mathrm{~nm}$ and $231.60 \mathrm{~nm}$, respectively. 

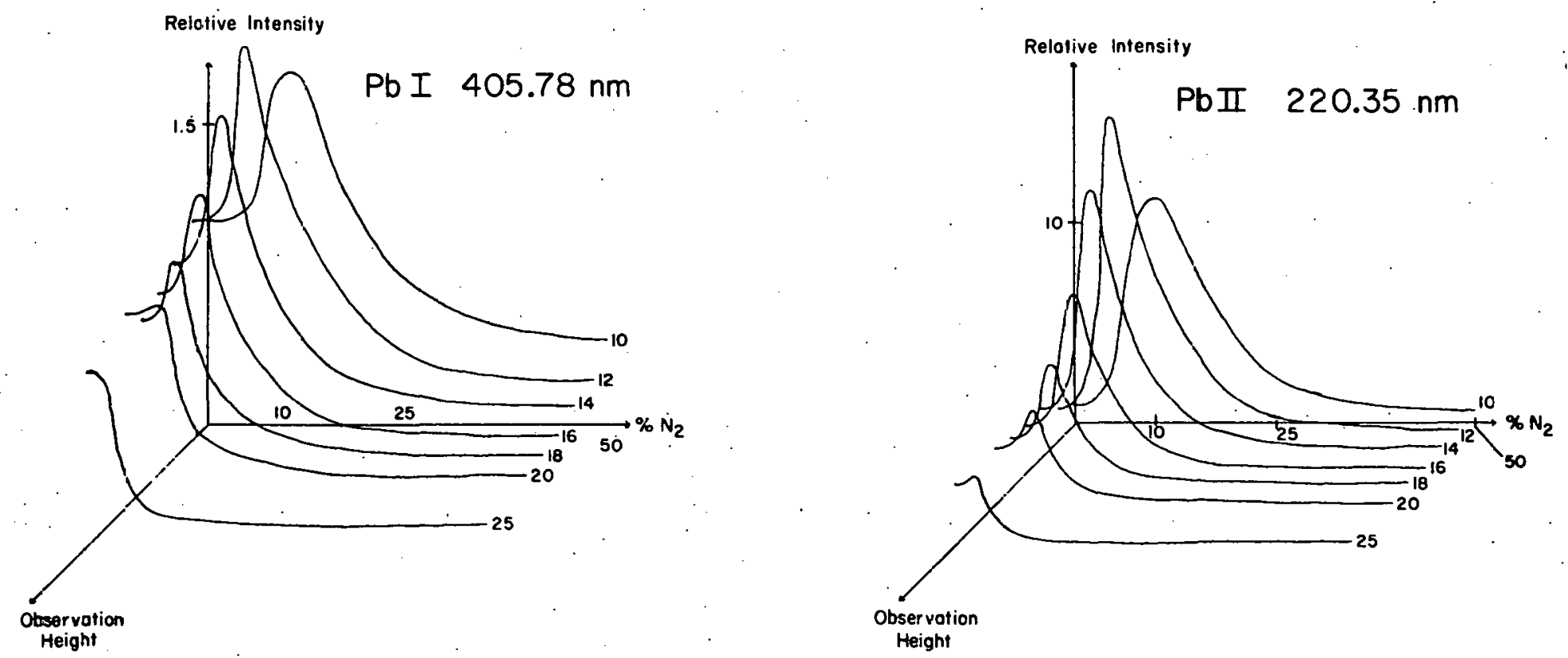

Figure 7. Effect of $\% \mathrm{~N}_{2}$ and observation height (mm) on the relative intensities of the lead atom and ion spectral lines at $405.78 \mathrm{~nm}$ and $220.35 \mathrm{~nm}$, respectively. 

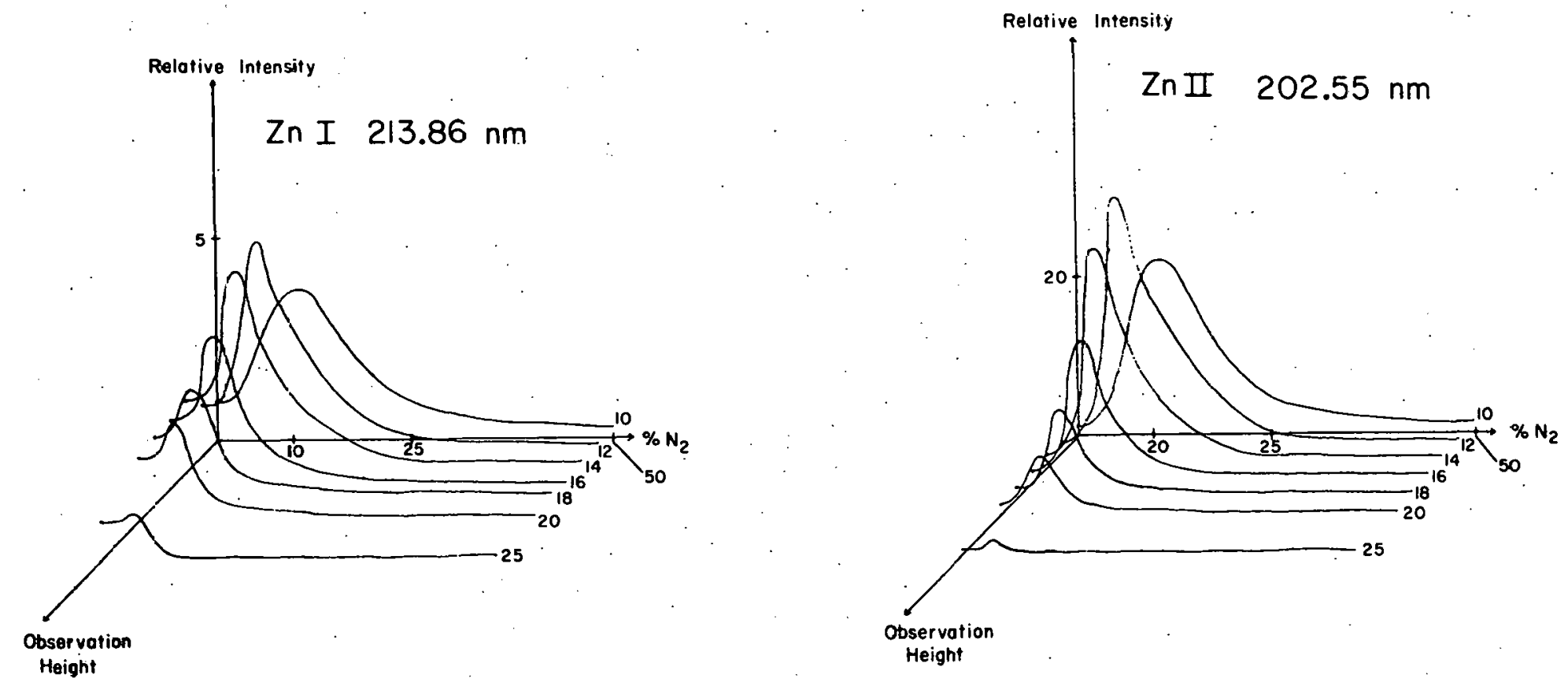

Figure 8. Effect of $\% \mathrm{~N}_{2}$ and observation height (mm) on the relative intensities of the zinc atom and ion spectral lines at $213.86 \mathrm{~nm}$ and $202.55 \mathrm{~nm}$, respectively. 
As can be seen from the figures, the volume of nitrogen added to the plasma coolant gas flow had a pronounced effect not only on the size and shape of the resulting discharge (Figure 4) but also the net analyte emission intensity observed. Several interesting characteristics of the nitrogen-argon plasmas became apparent with the examination of the response surfaces. For example, the relative intensity maximum occurred at decreasing $\% \mathrm{~N}_{2}$ for increasing observation height, a characteristic that the author believed was primarily due to the decreasing size of the discharge with increasing $\% \mathrm{~N}_{2}$. It was also apparent that the net emission intensity was more sensitive to changes in observation height in the nitrogen-argon plasmas than in those operated in argon atmosphere $\left(0 \% \mathrm{~N}_{2}\right)$.

The most prominent feature, however, was the observation that the relative intensity maximum for the nitrogen-argon plasma was never exceeded by the maximum obtained in the argon plasma. This signal cnhancement suggested that the nitrogenargon plasmas were hotter than the corresponding argon ICP. The experimental observation that the analyte ion (higher energy) lines exhibited a greater enhancement than the atom lines supported this suggestion.

The standard deviation of the intensity ratio, determined from ten consecutive and alternative net emission intensity measurements in the argon and the argon-7.5\% nitrogen 
plasmas at an observational height of $12 \mathrm{~mm}$ was $2 \%$. The total time span was approximately two hours for the determination; the test analyte (Cd) concentration was $0.05 \mu \mathrm{g} / \mathrm{ml}$. Wavelengths scans

Scans over the spectral range of the ARL QVAC 127 (System 1) were performed with the Jarrel1-Ash.spectrometer (System 2) while the plasma was operated with dry argon in the aerosol carrier gas flow. The scans obtained for the argon and the argon - $7.5 \%$ nitrogen plasmas at an observation height of 15 $\mathrm{mm}$ are shown in Figure 9. A log amplifier was employed in order to accommodate the signal intensity range of the $X-Y$ recorder without necessitating changes of the photomultiplier voltage.

The increased emission intensity of the cyanogen violet band system (band heads at $421.6,388.3$, and $359.0 \mathrm{~nm}$ degraded to the violet) in the nitrogen-argon plasma as compared to the argon plasma was the most prominent feature of these wavelength scans. Other molecular band spectra enhanced in the nitrogen-argon plasma were the $\mathrm{N}_{2}$ second positive (band heads at 337.1 and $315.9 \mathrm{~nm}$ ) and the $\mathrm{NH}$ (band head at $336.0 \mathrm{~nm}$ ) systems. This enhancement of the molecular band spectra, the net intensity of which increased with increasing observation height, was predictable based on similar observations with discharge tubes (45).

Wavelength scans over a selected region (210-240 nm) rich 


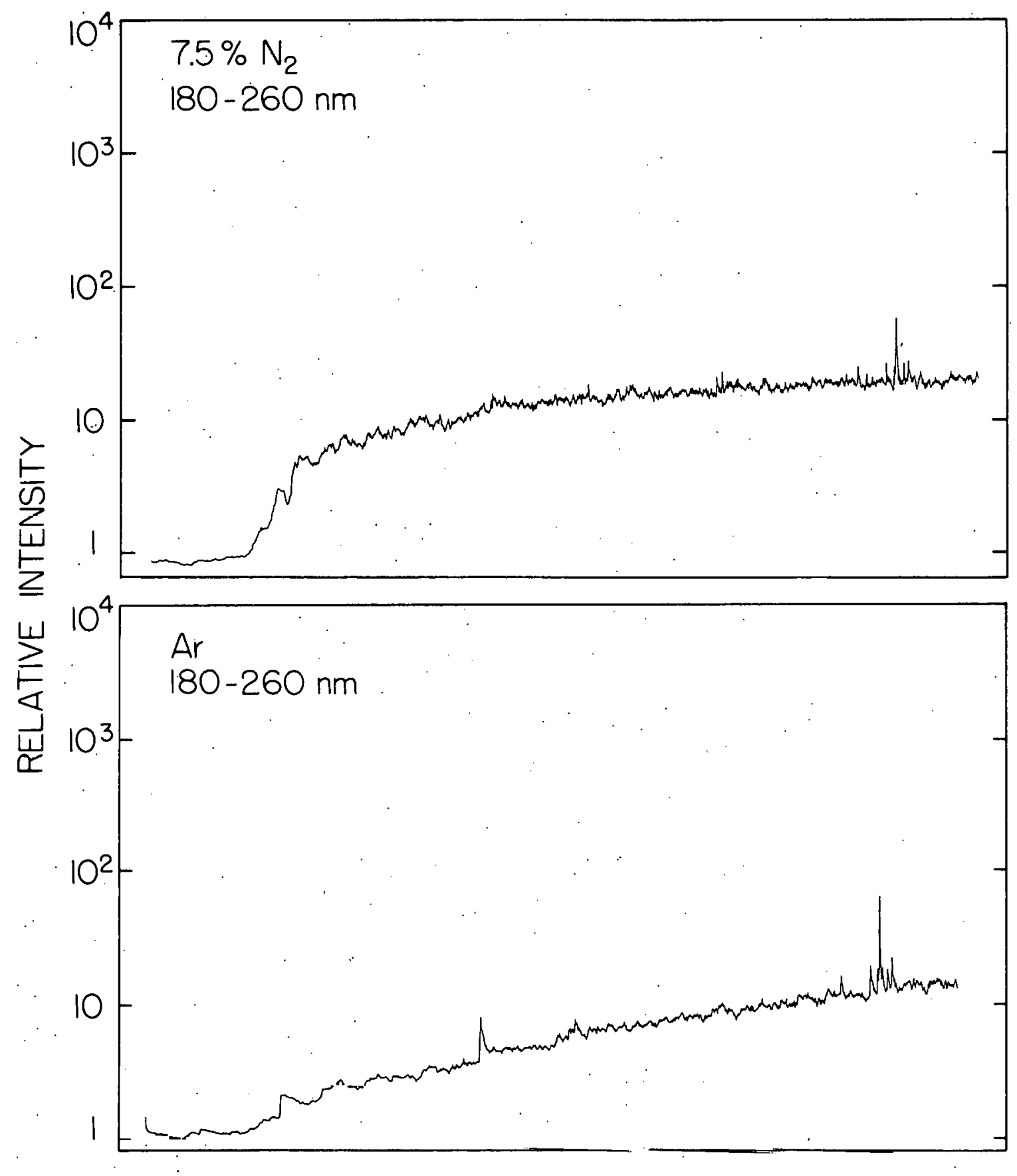

Figure 9. Wavelength scans for $\mathrm{Ar}$ and $\mathrm{Ar}-7.5 \% \mathrm{~N}_{2}$ plasmas. 


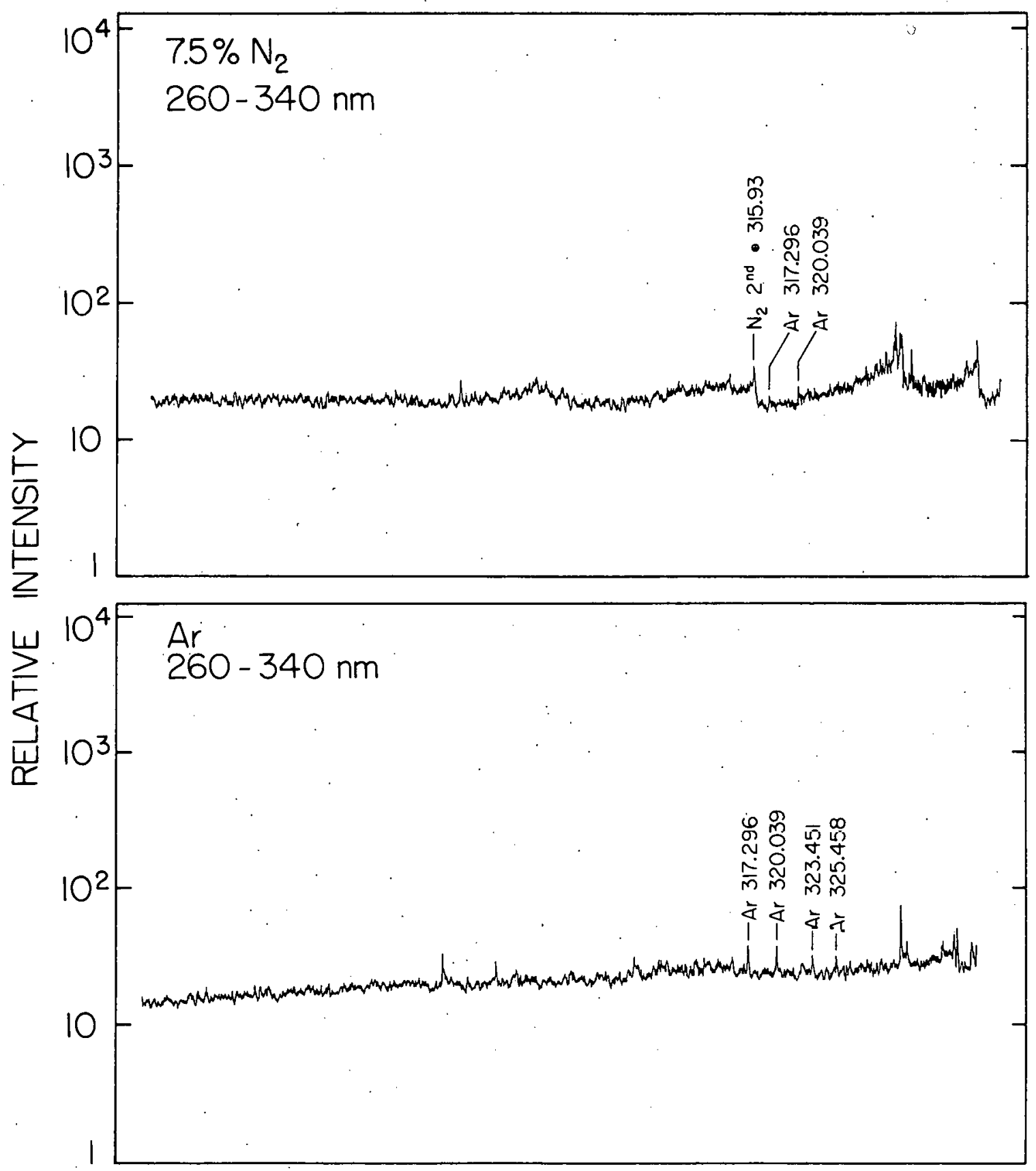

Figure 9. (continued) 


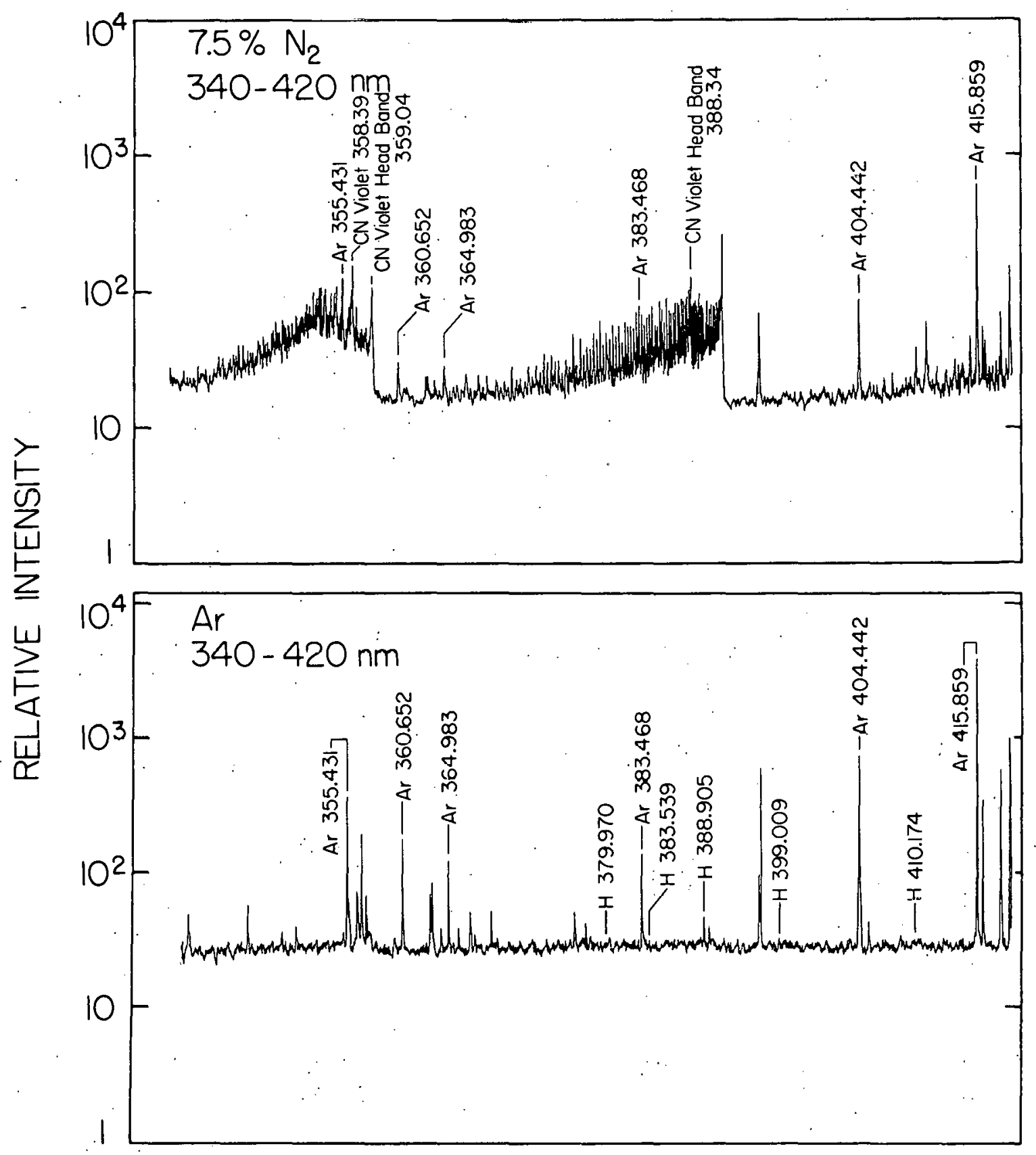

Figure 9. (continued) 


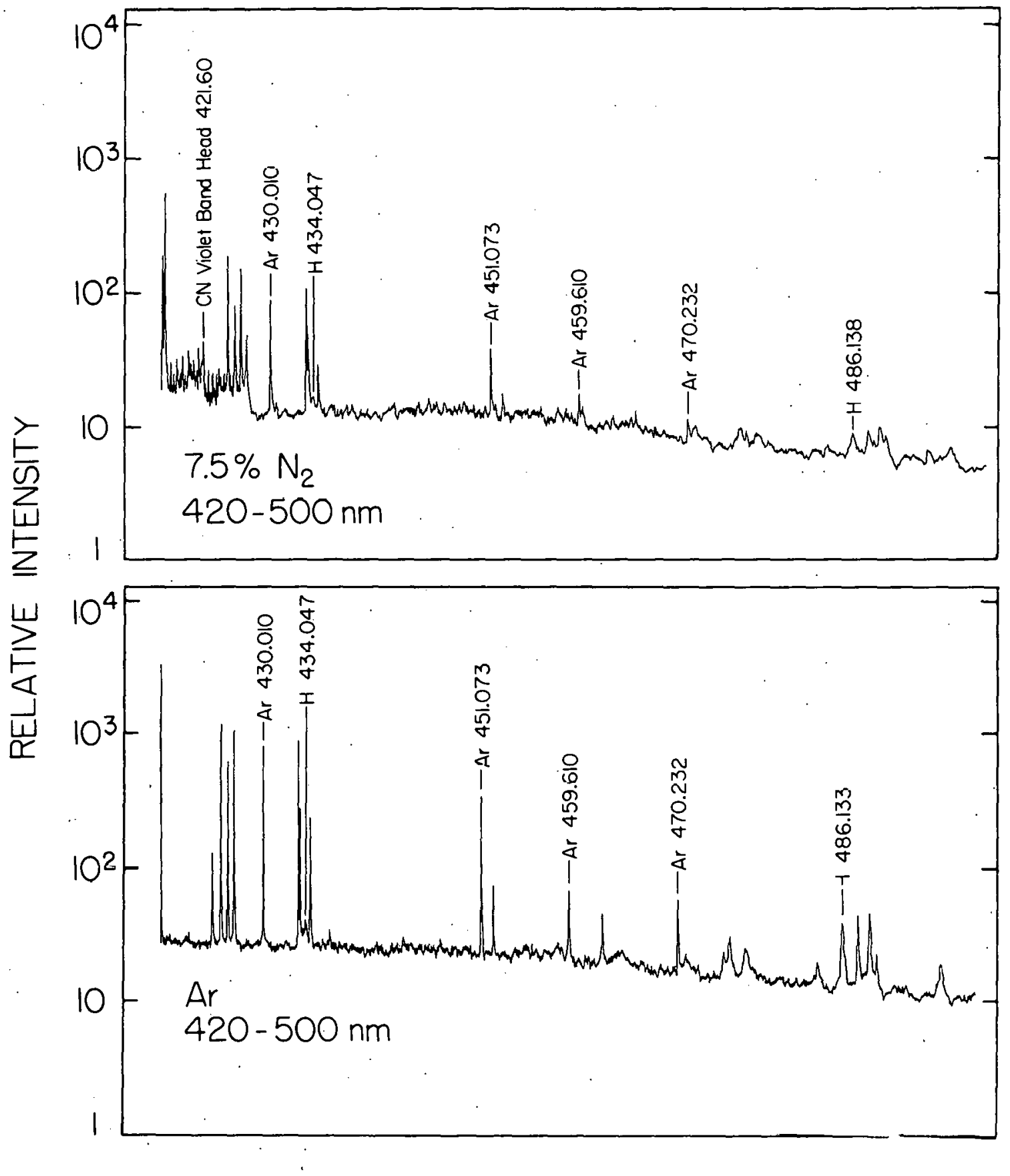

Figure 9. (continued) 
in nickel spectra were performed for both plasmas while ultrasonically nebulizing $1 \mu \mathrm{g} / \mathrm{ml} \mathrm{Ni}$ in $1 \%$ (vol) $\mathrm{HNO}_{3}$. The more intense emission lines of nickel over the spectral range examined were identified (46) and are shown in Figure 10.

As can be seen in the figure, the entire nickel spectra exhibited an enhancement in the nitrogen-argon ICP. In addition, the figure clearly illustrates the increase in the background emission intensity when a nitrogen-argon admixture was employed as the plasma discharge atmosphere. This latter observation further supported the author's suggestion that the addition of nitrogen to the plasma coolant gas flow increased the discharge temperature.

Effect of operating conditions on the extent of the observed signal enhancement

Since the operating conditions employed, i.e., raised torch and an auxiliary plasma gas flow, were not general operating procedures in this laboratory (15), the possibility existed that the net analyte signal enhancements observed in the preceding studies were biased. Therefore, the effect of various operating conditions on the net emission intensity of selected spectral lines were examined. The operating conditions employed for the determinations were as follows:

1. Raised torch, $1.5 \mathrm{\ell} / \mathrm{min}$ auxiliary plasma gas flow rate, and ultrasonic nebulization with desolvation of the sample aerosol; 


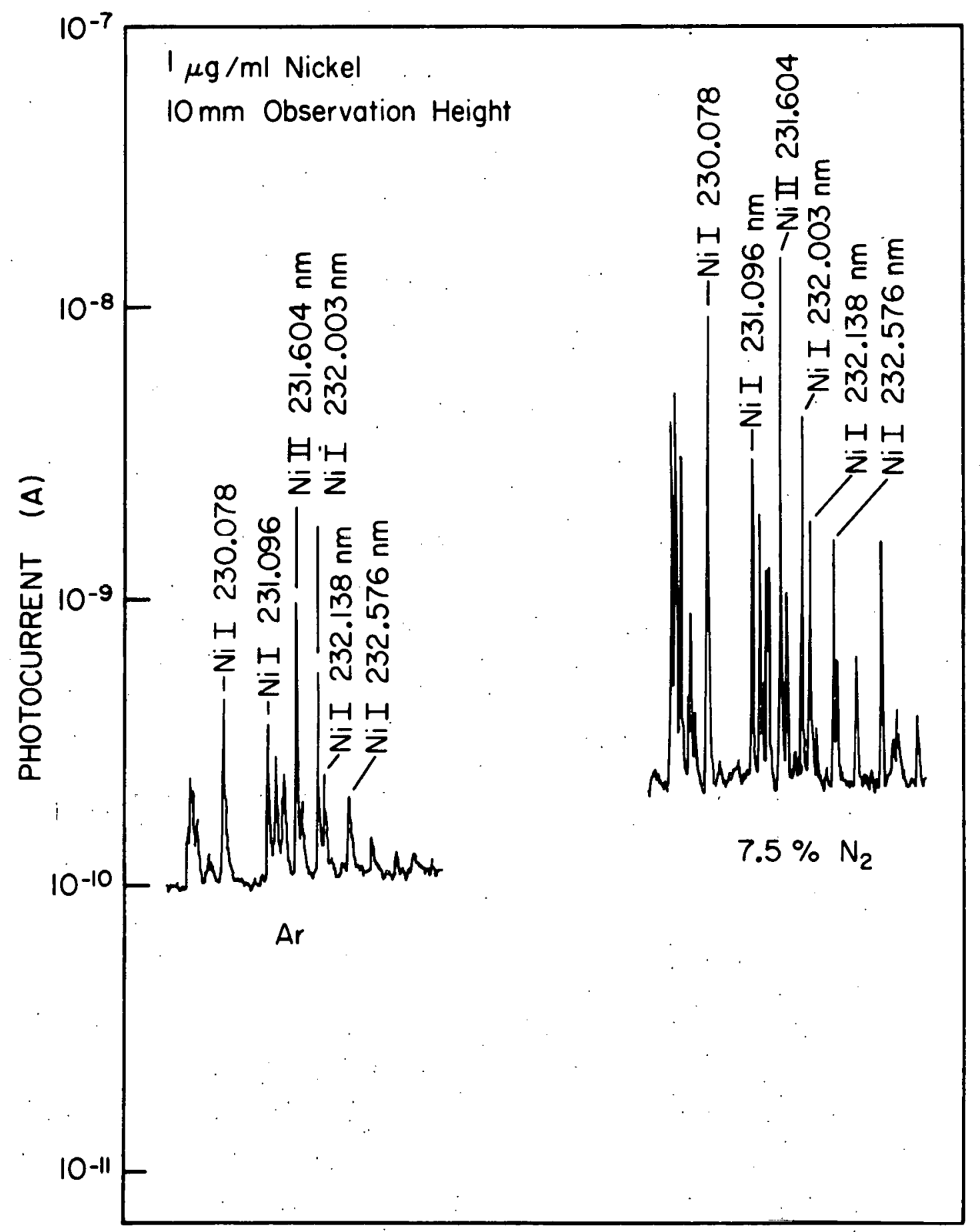

Figure 10. Enhancement of $\mathrm{Ni}$ emission in $\mathrm{Ar}-7.5 \% \mathrm{~N}_{2}$ plasma. 
2. Normal torch, no auxiliary plasma gas fllow, and ultrasonic nebulization with desolvation of the sample aerosol;

3. Normal torch, $1.5 \mathrm{l} /$ min auxiliary plasma gas flow rate, and ultrasonic nebulization with desolvation of the sample aerosol; and

4. Normal torch, $1.5 \mathrm{l} / \mathrm{min}$ auxiliary plasma gas flow rate, and pneumatic nebulization without desolvation of the sample aerosol.

Intensity data were collected for plasmas with $0,4.5$, $6.0,7.5$, and $9.0 \%$ nitrogen in the coolant gas flow. The maximum nitrogen concentration ( $9 \%$ ) was limited by the tolerance of the plasma operated with the torch in the normal position without an auxiliary flow (Case 2). The response surfaces obtained under the above operating conditions are shown for the Mn II (257.61 nm) and AI I (308.22 nm) spectral lines in Figures 11 and 12, respectively. As can be seen from the figures, for each operating condition employed the net analyte emission intensity was greater in the nitrogen-argon plasmas than in the argon plasma.

The maximum intensity ratios, i.e., the maximum net analyte emission in the nitrogen-argon plasma divided by the maximum net analyte emission intensity in the argon plasma, for all the spectral lines investigated under the various operating conditions are listed in Table 4. Also listed in 

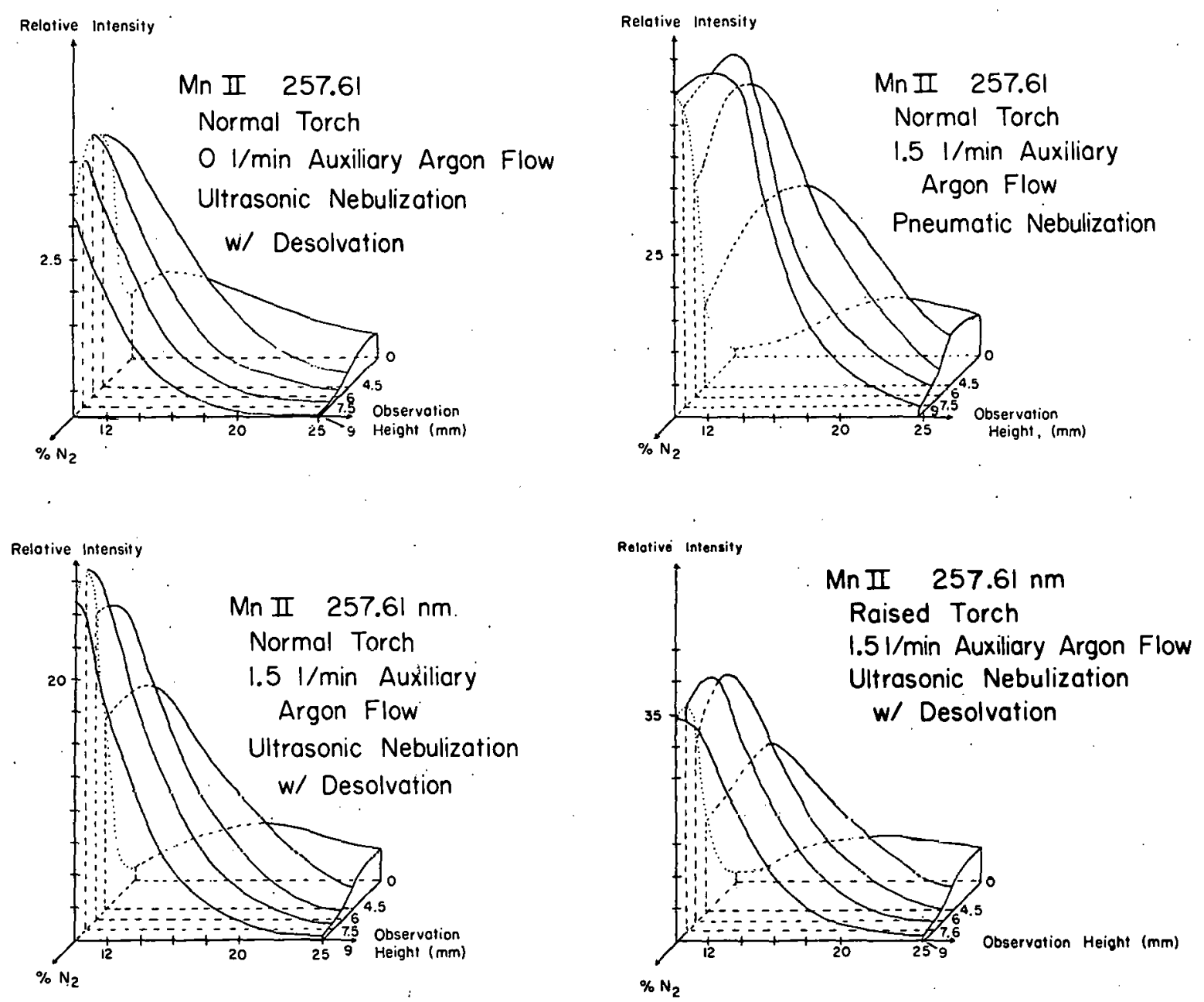

Figure 11. Response surface for Mn II at $257.61 \mathrm{~nm}$. 

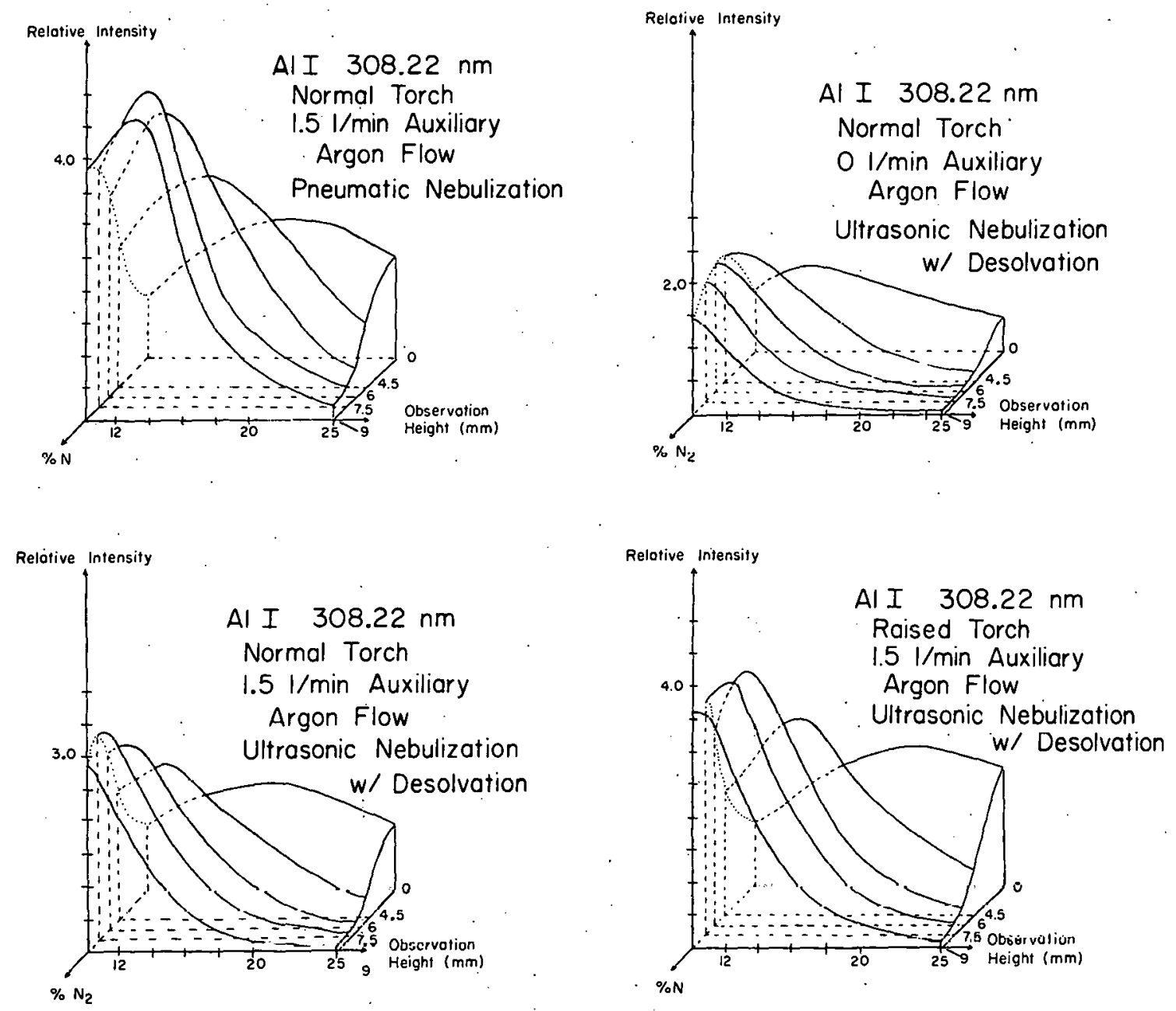

Figure 12. Response surface for Al I at $308.22 \mathrm{~nm}$. 
Table 4. Maximum intensity ratios observed under different operating conditions

\begin{tabular}{|c|c|c|c|}
\hline $\begin{array}{l}\text { Spectral } \\
\text { Line }\end{array}$ & $(\mathrm{nm})$ & $\begin{array}{r}\text { Torch position: } \\
\text { Auxiliary flow rate: } \\
\text { Nebulizer: }\end{array}$ & $\begin{array}{l}\text { Raised } \\
1.5 \text { l/min } \\
\text { Uitrasonic }\end{array}$ \\
\hline $\begin{array}{lr}\text { Al } & \text { I } \\
\text { As } & \text { I } \\
\mathrm{Ba} & \mathrm{II} \\
\mathrm{Bi} & \mathrm{I}\end{array}$ & $\begin{array}{l}308.22 \\
193.76 \\
233.53 \\
223.06\end{array}$ & & $\begin{array}{l}2^{\mathrm{a}}(12){ }^{\mathrm{b}}(6.0)^{\mathrm{c}}(20)^{\mathrm{d}} \\
4(12) \quad(7.5) \\
8(12)(7.5) \\
2(20) \\
2(12)(7.5)(20)\end{array}$ \\
\hline $\begin{array}{lr}\mathrm{Cd} & \text { II } \\
\mathrm{Cd} & \text { I } \\
\mathrm{Co} & \text { II } \\
\text { Cr } & \text { II }\end{array}$ & $\begin{array}{l}226.50 \\
228.80 \\
238.89 \\
267.72\end{array}$ & & 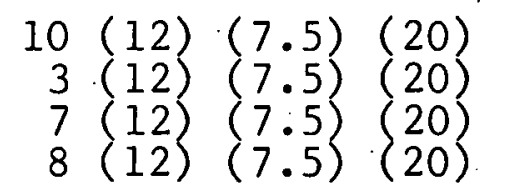 \\
\hline $\begin{array}{ll}\mathrm{Cr} & \mathrm{I} \\
\mathrm{Cu} & \mathrm{I} \\
\mathrm{Fe} & \mathrm{II} \\
\mathrm{Mn} & \mathrm{II}\end{array}$ & $\begin{array}{l}357.87 \\
324.75 \\
261.19 \\
257.61\end{array}$ & & 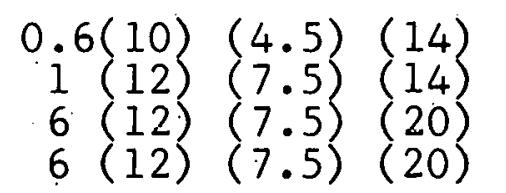 \\
\hline $\begin{array}{ll}\mathrm{Ni} & \mathrm{II} \\
\mathrm{Ni} & \mathrm{I} \\
\mathrm{Pb} & \mathrm{II} \\
\mathrm{Pb} & \mathrm{I}\end{array}$ & $\begin{array}{l}231 \cdot 60 \\
351 \cdot 51 \\
220 \cdot 35 \\
405 \cdot 78\end{array}$ & & $\begin{array}{llll}7 & (12) & (7.5) & (16) \\
1 & (12) & (6.0) & (14) \\
5 & (12) & (7.5) & (20) \\
2 & (12) & (7.5) & (12)\end{array}$ \\
\hline $\begin{array}{lr}\mathrm{Se} & \mathrm{I} \\
\mathrm{V} & \mathrm{II} \\
\mathrm{Zn} & \mathrm{II} \\
\mathrm{Zn} & \mathrm{I}\end{array}$ & $\begin{array}{l}196.03 \\
311.07 \\
202.55 \\
213.86\end{array}$ & & $\left.\begin{array}{r}4 \\
5 \\
20 \\
3(12) \\
3(12) \\
12\end{array}\right)\left(\begin{array}{l}7.5) \\
7.5 \\
7.5 \\
7.5)\end{array}\right)\left(\begin{array}{l}14 \\
20 \\
16 \\
14\end{array}\right)$ \\
\hline
\end{tabular}

antensity ratio $=$ maximum net intensity with $\mathrm{N}_{2}-\mathrm{Ar}$ plasma - maximum net intensity with Ar plasma.

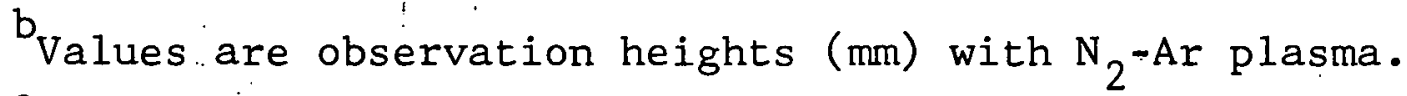

Values are $\% \mathrm{~N}_{2}$ in plasma coolant gas flow.

dValues are observation heights (mm) with Ar plasma. 
THIS PAGE

WAS INTENTIONALLY

LEFT BLANK 


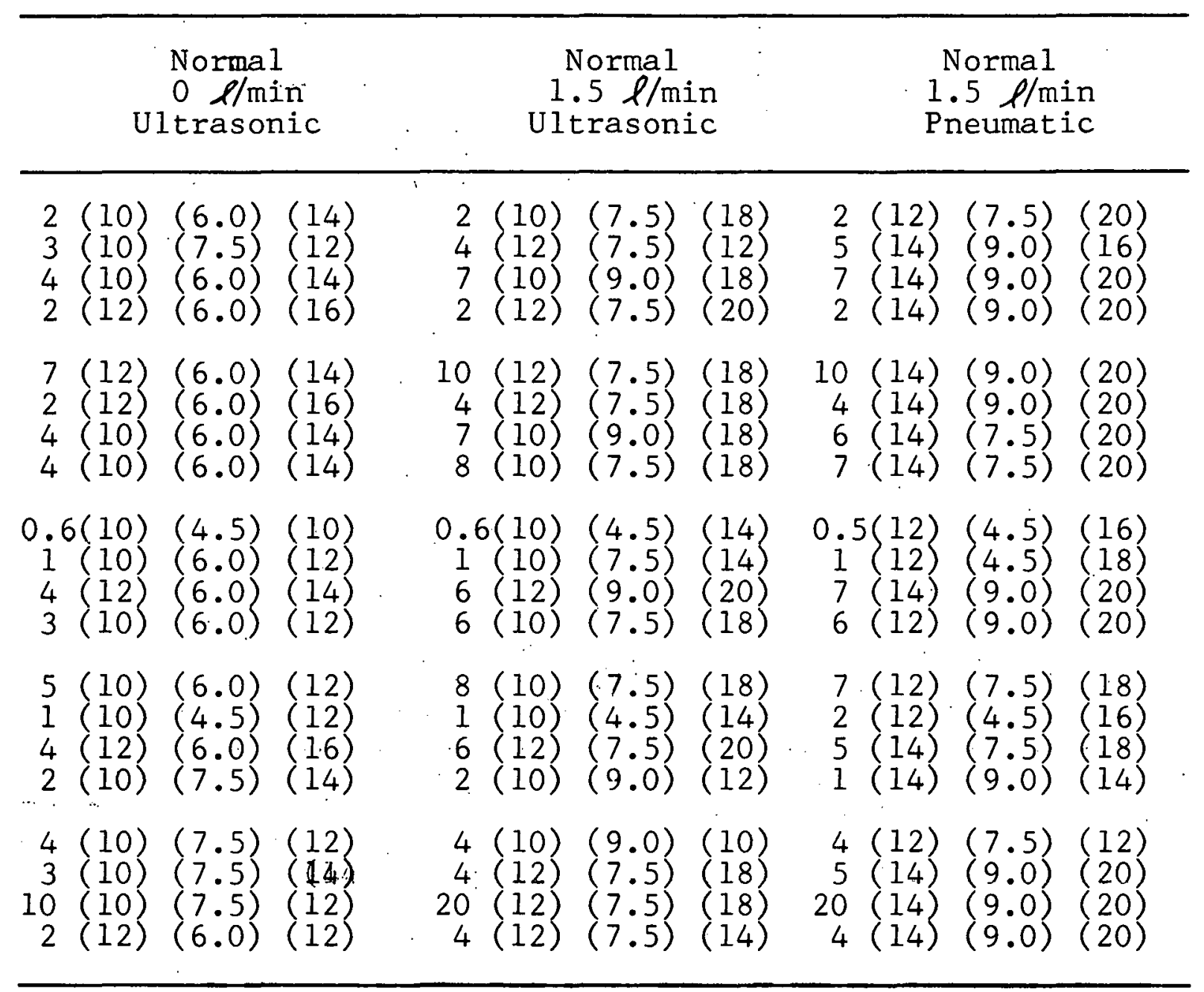


the table are the observation heights where these maxima occurred in the nitrogen-argon and argon plasmas (numbers in ()$^{b}$ and ()$^{d}$, respectively), as well as the corresponding $\%$ $\mathrm{N}_{2}$ in the plasma coolant gas flow (numbers in ()$^{c}$ ). For each of the operating conditions employed, there existed optimum observation height - \% nitrogen values for maximizing the net signal intensity. For example, when the plasma was operated with the torch in the normal position, without an auxiliary plasma gas flow, and with ultrasonic nebulization with desolvation of the sample aerosol (Operating condition set 2), a majority of the maximum signal enhancements occurred at an observation height of $10 \mathrm{~mm}$ in the argon - $6 \%$ nitrogen plasma. Two trends in the $\mathrm{Ar}-\mathrm{N}_{2}$ plasmas were also discernible from the data presented in Table 4; the increase in the auxiliary plasma flow rate required an increase in either the observation height or \% nitrogen, and the intensity ratio maxima occurred higher in the plasma when pneumatic nebulization (column 4) was employed as compared to ultrasonic nebulization with desolvation (column 3). This latter trend was due to the larger aerosol droplets obtained when the pneumatic nebulizer was employed (33): Detection limits

Detection limits were determined for a representative set of elements in a $1 \% \mathrm{HNO}_{3}$ solution. Five different sets of operating conditions were employed; those that were varied 
are listed in Table 5.

Table 5. Operating conditions varied for detection limit stúdy

\begin{tabular}{|c|c|c|c|c|c|}
\hline Component & I & II & II I & IV & V \\
\hline $\begin{array}{l}\text { Gas flows } \\
\text { Coolant } \\
\text { Auxiliary } \\
\text { Aerosol Carrier }\end{array}$ & $\begin{array}{l}\text { Ar } \\
\text { None } \\
\text { Ar }\end{array}$ & $\begin{array}{c}\text { Ar }-6 \% N_{2} \\
\text { None } \\
\text { Ar }\end{array}$ & $\begin{array}{c}\mathrm{Ar}-6 \% \mathrm{~N}_{2} \\
\mathrm{Ar} \\
\mathrm{Ar}\end{array}$ & $\begin{array}{c}\mathrm{Ar}-7.5 \% \mathrm{~N}_{2} \\
\mathrm{Ar} \\
\mathrm{Ar}\end{array}$ & $\begin{array}{l}\mathrm{Ar} \\
\mathrm{Ar} \\
\mathrm{N}_{2}\end{array}$ \\
\hline $\begin{array}{l}\text { Torch } \\
\quad \text { Position }\end{array}$ & Normal & Normal & Normal & Raised & Raised \\
\hline $\begin{array}{l}\text { Observation } \\
\text { Height }(\mathrm{mm})\end{array}$ & 15 & 12 & 15 & 12 & 15 \\
\hline Forward Power & $1100 \mathrm{~W}$ & $1100 \mathrm{~W}$ & $1100 \mathrm{~W}$ & $1100 \mathrm{~W}$ & $2000 \mathrm{~W}$ \\
\hline
\end{tabular}

In the case where the plasma was operated with a nitrogen aerosol carrier gas flow $(V)$, the incident $R F$ power was raised to $2000 \mathrm{~W}$ in order to overcome plasma instability problems (Table 3). Other operating conditions, such as sample uptake rate, gas flow rates, and signal measurement time, etc., were maintained at identical values for these determinations (Table 2); ultrasonic nebulization with desolvation was employed. The detection limits obtained on a simultaneous multielement basis for the various operating conditions employed are listed in Table 6. Also included in the table (column 6) are the detection limits obtained with the demountable plasma torch and an argon.- $6 \%$ nitrogen plasma (column III in Table 5). 
Table 6. Detection limits ( $\mathrm{g} / \mathrm{ml}$ )

\begin{tabular}{|c|c|c|c|c|c|c|c|}
\hline \multirow{2}{*}{$\begin{array}{l}\text { Spectral } \\
\text { line }\end{array}$} & \multirow[b]{2}{*}{$(\mathrm{nm})$} & \multirow[b]{2}{*}{ I } & \multicolumn{5}{|c|}{ Operating Conditions } \\
\hline & & & II & III & $\operatorname{III}^{\mathrm{a}}$ & IV & $\mathrm{V}$. \\
\hline $\begin{array}{lr}\mathrm{Al} & \mathrm{I} \\
\mathrm{As} & \mathrm{I} \\
\mathrm{Ba} & \mathrm{II} \\
\mathrm{Bi} & \mathrm{I}\end{array}$ & $\begin{array}{l}308.22 \\
193.76 \\
233.53 \\
223.06\end{array}$ & $\begin{array}{l}0.6 \\
8 \\
0.09 \\
3\end{array}$ & $\begin{array}{l}0.9 \\
3 \\
0.1 \\
5\end{array}$ & $\begin{array}{l}1 \\
3 \\
0.1 \\
2\end{array}$ & $\begin{array}{l}1 \\
2 \\
0.05 \\
3\end{array}$ & $\begin{array}{l}0.9 \\
3 \\
0.1 \\
5\end{array}$ & $\begin{array}{r}10 \\
60 \\
- \\
-\end{array}$ \\
\hline $\begin{array}{lr}\mathrm{Cd} & \text { II } \\
\mathrm{Cd} & \text { I } \\
\mathrm{Co} & \text { II } \\
\mathrm{Cr} & \text { II }\end{array}$ & $\begin{array}{l}226.50 \\
228.80 \\
238.89 \\
267.72\end{array}$ & $\begin{array}{l}0.3 \\
0.06 \\
0.3 \\
0.6\end{array}$ & $\begin{array}{l}0.2 \\
0.2 \\
0.2 \\
0.2\end{array}$ & $\begin{array}{l}0.06 \\
0.1 \\
0.2 \\
0.2\end{array}$ & $\begin{array}{l}0.1 \\
0.2 \\
0.4 \\
0.3\end{array}$ & $\begin{array}{l}0.2 \\
0.2 \\
0.2 \\
0.2\end{array}$ & $\begin{array}{r}6 \\
- \\
20 \\
50\end{array}$ \\
\hline $\begin{array}{ll}\mathrm{Cr} & \mathrm{I} \\
\mathrm{Cu} & \mathrm{I} \\
\mathrm{Fe} & \mathrm{II} \\
\mathrm{Mn} & \mathrm{II}\end{array}$ & $\begin{array}{l}357.87 \\
324.75 \\
261.19 \\
257.61\end{array}$ & $\begin{array}{l}0.2 \\
0.1 \\
1 \\
0.02\end{array}$ & $\begin{array}{l}1 \\
0.05 \\
1 \\
0.4\end{array}$ & $\begin{array}{l}1 \\
0.1 \\
0.5 \\
0.02\end{array}$ & $\begin{array}{l}0.9 \\
0.1 \\
1 \\
0.02\end{array}$ & $\begin{array}{l}1 \\
0.05 \\
1 \\
0.4\end{array}$ & $\begin{array}{l}- \\
0.4 \\
60 \\
4\end{array}$ \\
\hline $\begin{array}{lr}\mathrm{Ni} & \mathrm{II} \\
\mathrm{Ni} & \mathrm{I} \\
\mathrm{Pb} & \mathrm{II} \\
\mathrm{Se} & \mathrm{I}\end{array}$ & $\begin{array}{l}231.60 \\
351.51 \\
220.35 \\
196.03\end{array}$ & $\begin{array}{l}0.9 \\
0.9 \\
3 \\
6\end{array}$ & $\begin{array}{l}0.7 \\
2 \\
2 \\
1\end{array}$ & $\begin{array}{l}0.5 \\
3 \\
1 \\
1:\end{array}$ & $\begin{array}{l}0.8 \\
3 \\
3 \\
2\end{array}$ & $\begin{array}{l}0.7 \\
2 \\
2 \\
1\end{array}$ & $\begin{array}{r}80 \\
30 \overline{-} \\
90\end{array}$ \\
\hline $\begin{array}{lr}V & I I \\
\mathrm{Zn} & \mathrm{II} \\
\mathrm{Zn} & \mathrm{I}\end{array}$ & $\begin{array}{l}311.07 \\
202.55 \\
213.86\end{array}$ & $\begin{array}{l}0.1 \\
0.1 \\
0.09\end{array}$ & $\begin{array}{l}0.1 \\
0.1 \\
0.2\end{array}$ & $\begin{array}{l}0.1 \\
0.05 \\
0.1\end{array}$ & $\begin{array}{l}0.1 \\
0.1 \\
0.2\end{array}$ & $\begin{array}{l}0.1 \\
0.1 \\
0.2\end{array}$ & $\begin{array}{l}10 \\
10\end{array}$ \\
\hline
\end{tabular}

Data taken with demountable plasma torch. 
As can be seen from the table, the plasmas operated with nitrogen-argon admixtures in the plasma coolant gas flow (columns II through IV) yielded comparable detection limits; an indication that compromise conditions could be obtained for operating each plasma. In addition, these detection limits were comparable to those obtained with the plasma operating under normal conditions (column I). Also apparent from the table was the inferiority of the detection limits obtained for the plasma discharge operated with a nitrogen aerosol carrier gas flow (column $V$ ) when compared to the plasmas operated with the other gas flow configurations. This inferiority (greater than an order of magnitude) of detection limits for the $\mathrm{Ar}^{-\mathrm{N}_{2}}$ carrier gas plasma was not unexpected due to a similar behavior of the net intensity ratios and previous observations (21). However, the maximum net intensity ratios for the admixtures of nitrogen and argon in the plasma coolant gas flow (Table 4) would indicate that the improvement in detection limits for these plasmas should be more substantial.

Investigations into the cause of this behavior found a solution in the definition of the detection limit, i.e., the concentration of analyte required to give an average net emission intensity equal to three times the standard deviation of the background emission. Corresponding to the increase in the analyte emission intensity, there was an 
increase in the background emission intensity when nitrogen was added to the plasma coolant gas flow. Since the \% standard deviation of the background emission intensity remained relatively constant, the absolute standard deviation was greater for the $\mathrm{Ar}-\mathrm{N}_{2}$ plasmas; therefore, the detection limits showed only a limited improvement.

The data from columns III and III $^{a}$, i.e., plasmas operated under identical conditions but with different torches, indicated that the performance of the demountable plasma torch was comparable to that of the fused quartz design. The loss in the powers of detection, approximately a factor of two, was considered offset by both the convenience and versatility of the design. In addition, the plasma appeared to ignite more readily with the demountable torch; an observation that was believed to be related to the better defined electron and ion flow (47).

General discussion

Further evidence that the plasma operated with argonnitrogen admixtures in the coolant gas flow might be better than those operated in argon atmospheres was found in the examination on the effects of $100 \mu \mathrm{mol} / \mathrm{ml} \mathrm{Al}$ on the net emission intensity of $0.1 \mu \mathrm{mol} / \mathrm{ml} \mathrm{Ca}$ at the $393.3 \mathrm{~nm}$ spectral line ( $\mathrm{Ca}$ II). The net emission intensity ratios, i.e., the net intensity. with $100 \mu \mathrm{mol} / \mathrm{ml}$ Al divided by the net intensity without $A l$, for the calcium ion line were determined 
in the argon and the argon $\Leftrightarrow 6 \%$ nitrogen plasmas (condition II in Table 5). The results, obtained at observation heights of 15,20 , and $25 \mathrm{~mm}$, are shown in Table 7 .

Table 7. Effect of $100 \mu \mathrm{mol} / \mathrm{ml} \mathrm{Al}$ on Ca II emission from $0.1 \mu \mathrm{mol} / \mathrm{ml} \mathrm{Ca}$

\begin{tabular}{ccc}
\hline & \multicolumn{2}{c}{ Intensity ratio ${ }^{\mathrm{a}}$} \\
Observation height & Ar & Ar-6\% ${ }_{2}$ \\
\hline $15 \mathrm{~mm}$ & 0.86 & 0.96 \\
$20 \mathrm{~mm}$ & 0.97 & 1.02 \\
$25 \mathrm{~mm}$ & 1.03 & 1.04 \\
\hline
\end{tabular}

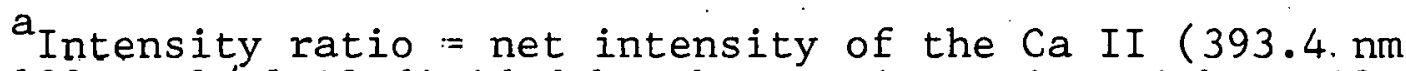
with $100 \mathrm{~mol} / \mathrm{ml} \mathrm{Al}$ divided by the net intensity without Al.

The most significant difference between the two plasmas was observed at $15 \mathrm{~mm}$ above the load coil; the argon plasma exhibited a signal suppression of $14 \%$, while the argon - $6 \%$ nitrogen plasma yielded only a $4 \%$ suppression. If this suppression is attributed to the occlusion of the $\mathrm{Ca}$ in a refractory aluminum oxide matrix formed during the aerosol droplet evaporation process, the data also suggested that the argon$6 \%$ nitrogen plasma was indeed hotter than the corresponding argon plasma at lower observation heights.

The results of this study have been supported by the study of aluminum oxide particle vaporization in both argon and argon-nitrogen plasmas by Capitelli et al. (24). 
Although Greenfield et al. (18) has presented evidence for the superiority of plasmas operated with nitrogen in the coolant gas flow, different operating conditions were employed. For example, the spectroscopic determinations were performed at observation heights higher than commonly utilized. In addition, the gas flow rates are significantly higher (22); the coolant, auxiliary, and aerosol carrier gas flow rates are 20-70, 10-35, and 2-3 l/min, respectively. The plasmas in this laboratory were not designed to be operated at the gas flow rates employed by Greenfield; howev$e r$, the data in Table 4 showed an increase in either observation height or \% nitrogen when the auxiliary plasma gas flow was increased. These data indicate that the performance of the plasmas employed in this study is comparable to that of Greenfield et al. (18), i.e., equivalent sets of compromise conditions were employed。 


\section{SUMMARY AND CONCLUSIONS}

The effects of the use of nitrogen in either the plasma coolant or aerosol carrier gas flows on the physical and spectrochemical properties of the ICP has been examined. While the plasma operated with nitrogen in the coolant flow exhibited a stability comparable to that of the argon plasma, the use of nitrogen in the aerosol carrier gas flow resulted in a plasma that was less stable. The detection limits obtained for the three plasmas exhibited a similar trend, i.e., those for the plasma with a nitrogen carrier gas were inferior to the others.

In addition, the use of nitrogen-argon admixtures in the plasma coolant gas flow yielded an increase in both the net analyte and the background emission intensities when the corresponding argon and nitrogen-argon plasmas were operated under various conditions. Furthermore, the effect of aluminum on the Ca II (393.4 nm) spectral line was reported for the 1000/1 Al/Ca molar ratio. At an observation height of $15 \mathrm{~mm}$, the signal depressions were 4 and $14 \%$ for the nitrogen-argon and the argon plasmas, respectively. The above experimental evidence suggested that the operation of the ICP with an Ar $-\mathrm{N}_{2}$ coolant gas might be hotter than the argon plasma currently in use in this laboratory.

The demountable plasma torch designed in collaboration with K. Olson yielded detection limits for 15 elements and 19 
spectral lines that were approximately within a factor of two of those obtained with the torch of fused quartz design (15). The design also appeared to offer a more readily initiated plasma discharge.

The experimental evidence presented supports the utilization of nitrogen-argon admixtures in the plasma coolant gas flow as altermate discharge atmospheres for inductively coupled plasma-atomic emission spectroscopy. In contrast, the experimental evidence shows that there is a deterioration in both physical and spectrochemical properties of plasmas operated with a nitrogen aerosol carrier gas. 


\section{SUGGESTIONS FOR FUTURE WORK}

Although consideration of the evidence suggests that the plasma operated with an argon-nitrogen coolant gas flow is hotter than the corresponding argon plasma, temperature measurements and comparisons are warranted. Also, some of the favorable analytical properties of argon ICP's, e.g., sensitivity of ion lines and small ionization interferences, have been attributed to energy transfer processes from metastable argon atoms $(48,49)$. Since energy transfer from metastable argon atoms to nitrogen which subsequently yield nitrogen metastables is likely $(50,51)$, the presence and effect of these nitrogen metastables in argon-nitrogen ICP's should be investigated.

The versatility of the demountable plasma torch should be utilized to its fullest extent by reexamining the effects of various torch configurations and positions on the properties of the ICP. 


\section{LITERATURE CITED}

1. S. Greenfield, I. Ll. Jones, and C. T. Berry, Analyst (London), 89, 713. (1964).

2. R. H. Wendt and V. A. Fassel, Anal. Chem., 37, 920 (1965).

3. R. H. Wendt and V. A. Fassel, Anal. Chem., 38, 337 (1966).

4. T. B. Reed, J. Appl. Phys., 32, 821 (1961).

5. T. B. Reed, Int. Science Tech., June 1962, p. 42.

6. J. D. Chase, J. Appl. Phys., 42, 4870 (1970).

7. H. U. Eckert, High Temp. Sci., 6, 99 (1974).

8. B. Waldie, Conference Proceedings International Round Table on the Study and Applications of Transport Phenomena in Thermal Plasmas, Odeillo-Fontromeu, France, September 1975, IV-9.

9. V. A. Fassel, Proc. 16th Coll- Spectr. Int., Heidelberg, 1971, Adam Hilger, London, 1972, p. 63.

10. G. W. Dickinson and V. A. Fassel, Anal. Chem., 4l, 1021 (1969).

11. R. H. Scott, V. A. Fassel, R. N. Kniseley, and D. E. Nixon, Anal. Chem., 46, 75 (1974).

12. D. J. Kalnickey, R. N. Kniseley, and V. A. Fassel, Spectrochim. Acța, 30B, 511 (1975).

13. G. F. Larson, V. A. Fassel, R. H. Scott, and R. N. Kniseley, Anal. Chem., 47, 238 (1975).

14. C. C. Butler, R. N. Kniseley, and V. A. Fassel, Anal. Chem., 47, 825 (1975).

15. V. A. Fassel and R. N. Kniseley, Anal. Chem., 46, 1110A 1155 A (1974). 
16. V. A. Fassel, ASTM Spec. Tech. Pub. 618, 22-42 (1977).

17. V. A. Fassel, Plenary Lecture at International Symposium on Analytical Chemistry in the Exploration, Mining, and Processing of Materials, Johannesburg, RSA, August 1976.

18. S. Greenfield, H. McD. McGeachin, and P. B. Smith, Talanta, 23, 1 (1976).

19. P. W. J. M. Boumans and F. J. de Boer, Proc. Anal. Divn. Chem. Soc., 12, 140 (1975).

20. S. Greenfield, Proc. Soc. Anal. Chem., 2, 111 (1965).

21. S. Greenfield, Metron, 3, 224 (1971).

22. S.Greenfield, Proc. Anal. Divn. Chem. Soc., 13, 279 (1976).

23. S. Greenfield and P. B. Smith, Anal. Chim. Acta, 59, 341 (1972).

24. M. Capitelli, F. Cramarossa, L. Triolo, and E. Molinari, Combust, Flame, 15, 23 (1970).

25. D. Truitt and J. W: Robinson, Anal. Chim. Acta, 49, 401. (1970).

26. D. Truitt and J. W. Robinson, Anal. Chim. Acta, 노, 61 (1970).

27. S. Greenfield and P. B. Smith, Anal. Chim. Acta, 57, 209. (1971).

28. S. Greenfield, I. Ll. Jones, H. Mon. McGeachin, and

P. B. Smith, Anal. Chim. Acta, 74, 225 (1975).

29. C. Veillon and M. Margoshes, Spectrochim. Acta, 23B, 503 (1968).

30. G. F. Larson, Ph.D. Thesis, Iowa State University, Ames, Iowa, 1976.

31. P. W. J. M. Boumans and F. J. de Boer, Spcctrochim Acla, 30B, 309 (1975).

32. P. W. J. M. Boumans and F. J. de Boer, Spectrochim. Acta, 31B, 355 (1976) 
33. K. W. Olson, W. J. Haas, Jr., and V. A. Fassel. Anal. Chem., 49, 632 (1977).

34. V. A. Fassel, C. A. Peterson, F. N. Abercombie, and

R. N. Kniseley, Anal. Chem., 48, 516 (1976).

35. R. N. Kniseley, H. Amenson, C. C. Butler, and V. A. Fassel, Appl. Spectrosc., 28, 285 (1974).

36. R. K. Winge, V. A. Fassel, R. N. Kniseley, E. L. DeKalb, and $W$. J. Haas, submitted for publication in Spectrochim. Acta, 27B, 391 (1972).

37. R. M. Dagnall, D. J. Smith, T. S. West, and S. Greenfield, Anal. Chim. Acta, 54, 397 (1971).

38. P. W. J. M. Boumans and F. J. de Boer, Spectrochim. Acta, 27B, 391 (1972).

39. J. M. Mermet and C. Trassy, Appl. Spectrosc., 31, 237 (1977):

40. M. B. Denton and D. L. Windsor, Pittsburgh Conference on Analytical Chemistry and Applied Spectroscopy, Cleveland, OH, March 1976, No. 294.

41. IUPAC Commission on Spectrochemical and Other Optical Procedures for Analysis, Pure Appl. Chem., 45, 99 (1976).

42. G. W. Dickinson, Ph.D. Thesis, Iowa State University, Ames, IA, 1969.

43. M. L. Thorpe, NASA Contractors Report CR-1143, 1968.

44. P.W. J. M. Boumans, ICP Newsletter, 1 (1976).

45. R. W. B. Pearse and A. G. Gaydon, "The Identification of Molecular Spectra", John Wiley \& Sons, Inc., New York, 1950 .

46. W. F. Meggers, C. H. Corliss, and B. F. Scribner, "Tables of Spectral-Line Intensities, Part I", National Bureau of Standards Monograph 145, 1972.

47. J. L. Genna, K. M. Barnes, and C. D. Allemand, Anal. Chem., 49, 1450 (1977).

48. J. M. Mermet, ‥ ‥ Acad. Sc. Paris, 281B, 273 (1975). 
49. P. W. J. M. Boumans and F. J. de Boer, submitted for publication in Spectrochim. Acta, Part B.

50. E. S. Fishburne, J. Chem. Phys., 47, 58 (1967).

51. A. P. D'Silva and V. A. Fassel, Anal. Chem., 44, 2115 (1972). 


\section{ACKNOWLEDGMENTS}

The author appreciates this opportunity to express his sincere thanks to Dr. Velmer A. Fassel for his patience, understanding, and guidance. Special thanks are also due to Ken Olson for his assistance in the design of the demountable plasma torch and to E. M. Layton for his suggestions on data presentation.

Words alone cannot express the debt of gratitude owed to Ruthann for her consideration and encouragement and to Kathryn Leigh for being the light of my life. Without either of them this endeavor would have been pointless. 